\title{
Modelling wind turbine degradation and maintenance
}

\author{
Bryant Le and John Andrews \\ Nottingham Transportation Engineering Centre, University of Nottingham
}

\begin{abstract}
This paper presents an asset model for offshore wind turbine reliability accounting for the degradation, inspection and maintenance processes. The model was developed based on the Petri Net method which effectively captures the stochastic nature of the dynamic processes through the use of appropriate statistical distributions. The versatility of the method allows the details of the degradation and maintenance operations to be incorporated in the model. In particular, there are dependent deterioration processes between wind turbine subsystems; complex maintenance rules; and the incorporation of condition monitoring systems for early failure indication to enable replacement prior to failure. The purpose of the model is to predict the future condition of wind turbine components and to investigate the effect of a specified maintenance strategy. The model outputs are statistics indicating the performance of the wind turbine components, these include the probability of being in different condition states, the expected number of maintenance actions as well as the average number and duration of system downtime under any maintenance strategy.
\end{abstract}

Keywords: wind turbine, Petri net, degradation, maintenance modelling. 


\section{Introduction}

Wind power is becoming the world's fastest growing renewable energy resource. In the UK, as of 2014, there are 1,075 offshore wind turbines and their combined total capacity is 3,653MW [1]. The UK government has confirmed the support for the wind energy industry with an extensive programme of planning and constructing new offshore wind farms [2]. With this trend, the total turbine asset portfolio will continue to increase, as will the proportion of turbines that have been in lengthy operation and are therefore aging. This provides a significant challenge for the management of these assets.

Offshore wind turbines are located at remote sites which commonly experience harsh conditions, therefore the cost of repair is high due to the special equipment and vessels required to carry out the task. Additionally, the waiting time for a suitable weather window increases the wind turbine downtime resulting in loss of revenue. Thus, the demand for high reliability and planned maintenance becomes critical. Condition monitoring systems (CMS) facilitate maintenance management and increase system availability [3]. CMSs are used to continuously monitor the performance of wind turbine components, and determine the optimal time for maintenance or component replacement prior to wind turbine component failures. It can be seen that, with the CMS widely deployed in the industry, the incorporation of CMS into the asset management model is critical. Despite the benefits of CMSs, the asset management model however should also account for CMS failures or malfunctions [4].

Several mathematical models have recently been introduced to predict the degradation and maintenance of wind turbines. Sayas and Alan [5] proposed a probabilistic model that considers the stochastic nature of the failure and repair processes of wind turbines. The model considers two states: 'up' and 'down' of the wind turbines and uses Markov analysis to investigate the performance of the wind turbine. Nilsson and Bertling [6] presented a reliability-centered maintenance (RCM) method to demonstrate the effect of different maintenance strategies based on the system reliability and the total maintenance cost. Besnard and Bertling [7] developed a Markov deterioration model in which the component states are: good, minor degradation, advanced degradation, major degradation and failure. These condition states are adopted from Eggen et al. [8] who categorises a component's continuous degradation into a generic 5 condition states. The method was demonstrated by evaluating the expected life cycle maintenance costs for the wind turbine blades. McMillan and Ault [4] also proposed that the deterioration and maintenance processes of a wind turbine can be captured via the use of a Markov Chain, and a Monte Carlo simulation is used to obtain statistical metrics that indicate the performance of a system. Three component conditions were adopted in this study which are: up (fully up), down (failed) and intermediate (derated); the intermediate state is the state where the abnormal condition of the component is observed. There are several models that incorporate information from the CMS on the current component states to schedule appropriate maintenance actions. They utilise the partially observed Markov decision process and stochastic discrete event approaches as presented in Byon, Ntaimo and Ding [9] and Perez, Ntaimo, Byon and Ding [10] respectively. The application of these models is limited to only a single component, the gearbox, in the wind turbine. 
This paper proposes a wind turbine asset management model based on the Petri Net method. The Petri Net method has been adopted to model maintenance in many applications [11], and is well suited to model dynamic processes such as the degradation and maintenance experienced in wind turbines. Furthermore, due to the flexibility of the method, interactions between subsystems or complexities in the maintenance rules such as those which govern opportunistic maintenance can be modelled in a simple manner. The asset model developed can be used to investigate the effects of different maintenance strategies, predict future asset condition, and also the expected wind turbine downtime due to component failure. The model also incorporates CMS in the inspection and monitoring process. For a component where CMS is available, the component condition is continuously monitored. This paper also demonstrates the application of the model to a wind turbine system.

\section{Wind turbine system}

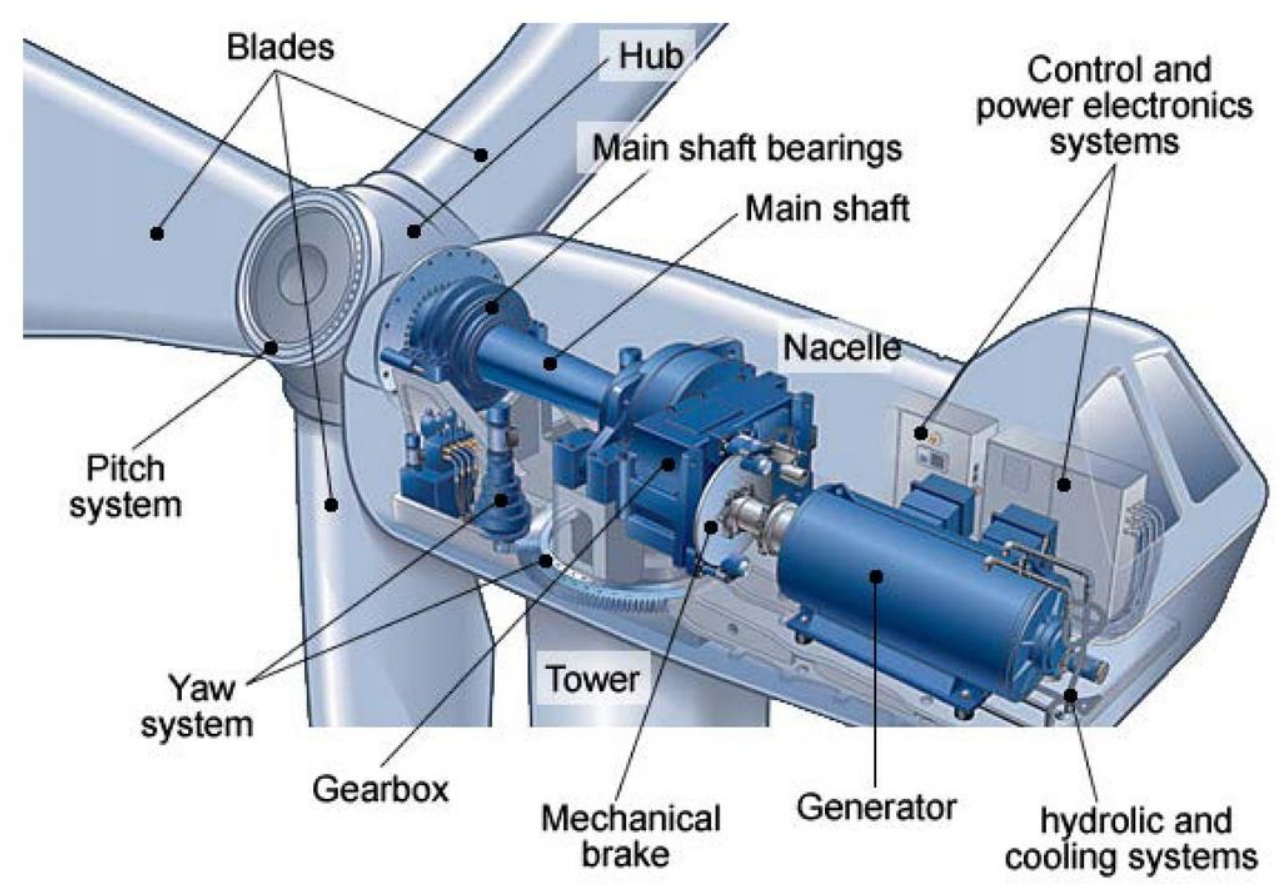

Figure 1: Wind turbine main subsystems (reprinted/reproduced with permission from [12])

Figure 1 illustrates the main subsystems and components in a wind turbine. In this section, the description and function of each subsystem and their components are discussed. This section also focuses in detail on the degradation conditions, as well as the condition monitoring procedure and related maintenance actions.

\subsection{Power generation drivetrain system}

The drivetrain comprises: the main shaft, the gearbox and the main bearings. The main shaft transmits torque from the hub to the gearbox. The gearbox increases the rotational speed of the main shaft from very low revolutions per minute (rpm) to the higher rpm required to drive the electric generator. The main bearings provide support for the main shaft in their positions while allowing rotary motion at minimum friction. The gearbox is one of the heaviest and most expensive components, its failure is among the failures resulting in the longest average 
downtime [13], thus, it contributes the highest percentage of failure downtime and has a significant impact on wind turbine production availability [14]. The failures of the gearbox include inadequate lubrication, gearbox bearing failure or gear teeth detachment [15]. Beside these, the majority of failures $(60 \%)$ of the drivetrain originate from the failure of bearings [16]. Lubrication oil is another important component in a wind turbine drivetrain. The main functions of the lubricant are to reduce friction and wear by introducing a film between the moving parts, to dissipate heat generated by contact friction, and finally to protect components from oxidation and corrosion. The condition of the lubrication has a significant effect on the degradation process of the drivetrain system [13] and this is taken into account in the modelling performed in this paper.

\subsection{Auxiliary systems (hydraulic, braking, yaw, pitch)}

The three main auxiliary systems are: the pitch, yaw and braking systems. The pitch system comprises of hydraulic actuators (hydraulic cylinders and piston rods) and pitch bearings. The pitch system function is to adjust the blade pitch angle to optimise the power output based on the wind speed, it also feathers the blades to minimise wind loads during stand still under extreme wind conditions. The yaw system orientates the rotor to the wind direction to maximise the wind energy conversion. The yaw system consists of a yaw driver/actuator, yaw bearing, gear, and brake system. The braking system locks the wind turbine position in non-operational mode such as under maintenance or stormy weather. In some types of wind turbines, the braking system is also used to reduce the power output in high wind conditions where the wind speed exceeds the maximum allowable. The brake system consists of a brake disc, brake pads and callipers. The hydraulic system powers these three main auxiliary systems. The main components of the hydraulic system are: the pumps, valves and pipes.

\subsection{Rotor system}

The wind turbine rotor system includes the blades and the hub. The number of blades varies according to different wind turbine designs, however, three blades are the most common. The blades are usually made from fibre-reinforced composite materials because of their high strength and stiffness with low weight properties. According to Ciang et al. [17], blade failures are one of the biggest number of structural incidents recorded. These failures include whole blade failures and the break off of pieces of the blade. The breaking of blades also increases of risk of failures of the tower and nearby wind turbines in a wind farm. The blades often fail as a result of cracks arising from fatigue or material defects [18, 19]. Lightning strikes and ice build-up are also common known causes of blade failures. The cost of the blades accounts for $15-20 \%$ of the total turbine cost, thus blade damage requires extensive repair with a long down time [20]. Furthermore, even minor blade damages may cause unbalance in the rotating mass which induces extra stress that speeds up the degradation process of the wind turbine [21]. The hub provides blade attachment and transfers the rotational force from the blades to the main shaft and is generally cast from steel. The hub also contains the pitch systems.

\subsection{Power system}

The power system of an offshore wind turbine often comprises: an electrical generator to convert mechanical torque to electromagnetic torque, a frequency converter, and a transformer 
to step up the frequency and voltage levels to match the grid requirements. Many studies [2224] show that in the power system, the contribution to the wind turbine failure for the three sub-systems: frequency converter, generator and transformer are $13 \%, 7 \%$ and $2 \%$ respectively. The contributions to the overall downtime are $18 \%, 11 \%$ and $2 \%$ respectively, so the total contribution of the power system to the wind turbine downtime is significant at $31 \%$. For the generators, some of the major faults are: bearing failures, short circuits of a stator or rotor winding, dynamic eccentricity, broken rotor bars of cracked end-rings, and air gap eccentricities. Furthermore, a study [25] has shown that about $40 \%$ of failures are related to bearings, $38 \%$ to the stator and $10 \%$ to the rotor.

\subsection{Structures}

The wind turbine structure includes the tower, the nacelle and the foundation. The tower provides support to the nacelle which encases the wind turbine assembly. The tower is a tubular steel structure which often has an elevator mechanism to provide access to the nacelle. The tower diameter and strength depend on the weight of the nacelle and the expected wind loads, typical tower heights for offshore wind turbines are around $60-100 \mathrm{~m}$. The nacelle provides protection to the wind turbine components from the external environment. These are often made from composite materials because of their light weight, good corrosion resistance and good electrical insulation. The foundation carries the weight of all wind turbine components, in offshore wind turbines, the foundation goes deep into the sea bed.

\subsection{Sensors and condition monitoring systems}

Condition monitoring and fault diagnosis are an important measure for predictive maintenance and condition based maintenance of wind turbine operation [26]. Modern wind turbines typically have about 2000 sensors [27]. These sensors, applicable for each specific sub-system, are connected to control systems where the fault detection algorithms analyse the measurement to give the immediate condition of the wind turbine components. In the model developed in this paper, each wind turbine sub-system has its own condition monitoring system (CMS), and a CMS unit contains both sensors and fault detection algorithms (Figure 3).

\subsection{Component condition states}

Previous sections discussed the main subsystems and components in a wind turbine. In this paper, the considered wind turbines components are shown in Figure 3 and are also listed in Table A1 in the Appendix. Figure 3 gives an overview of the degradation modes, condition monitoring, inspection and maintenance processes related to all the wind turbine sub-systems. It can be seen that, for each component, the degradation process is described by several degraded condition states, which are derived by the installation of several condition monitoring and fault detection methods. The states are defined based on threshold (alarm) levels for when the component is considered to change its condition. For example, Figure 2 illustrates the degradation process of the generation drivetrain system with the application of condition monitoring. The component starts in a normal working condition, excessive vibration detected at time $T_{1}$ provides a pre-warning time until it reaches critical condition (at $T_{2}$ ) where excessive vibration and heat generation are detected. Ultimately, the component reaches the failure condition (at $\mathrm{T}_{3}$ ). These condition states are adopted, thus, there are four condition states for 
three drive train components which are: normal, degraded, critical and failed as shown in Figure 3. Generally in a real application, the thresholds or events T1-3 are specified in the fault classification algorithm which triggers an alarm when the component is exhibiting an abnormal condition. The algorithm can be based on several approaches such as neural network, wavelet analysis, etc... Moreover, different wind turbine components have different critical characteristics (e.g. temperature, vibration, current, etc.), therefore detail definitions of events T1-3 should be defined uniquely for each component. In this paper, the condition of the drivetrain components is continuously monitored so that any change in their state is revealed immediately. Similarly, the condition states are derived for other components, with the exception of components (such as the frequency converter and the transformer) where condition monitoring is often not applicable because their failures are sudden, then there are only two condition states considered: normal and failed states.

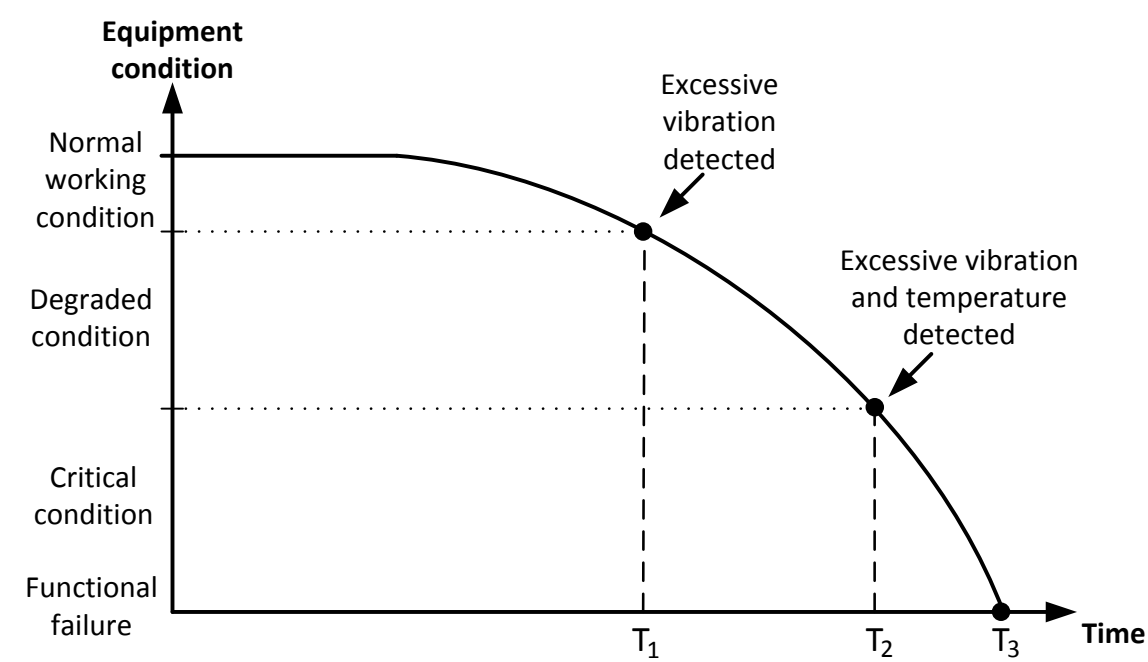

Figure 2: Degradation process of the drivetrain components and condition threshold triggered by vibration and temperature sensors.

Figure 3 shows, for each sub-system, the condition monitoring systems (CMS) which comprise of sensors and fault detection algorithms to detect changes in the component condition. It can also be seen from the diagram that some component conditions are not monitored using condition monitoring and these conditions are only revealed through onsite inspections. Additionally, the CMS may fail to detect degraded conditions or falsely indicate a degraded state. This is taken into account in the modelling in this paper. Three condition states of a CMS are considered: normal (working), fail, and false indication states. When the CMS fails, the component condition is not monitored and its condition is unrevealed until it is next inspected or when the CMS starts working again. In the false indication state, the condition monitoring system gives the wrong indication of the component condition. The effect of this could be that the maintenance is triggered for a problem that does not exist, or maintenance is not applied on a component which requires attention. The latter effect is similar to when the CMS has failed. Once the wind turbine component conditions are known, appropriate maintenance actions can be applied and depending on the condition states. There are several types of maintenance considered and they are discussed in the next section. 


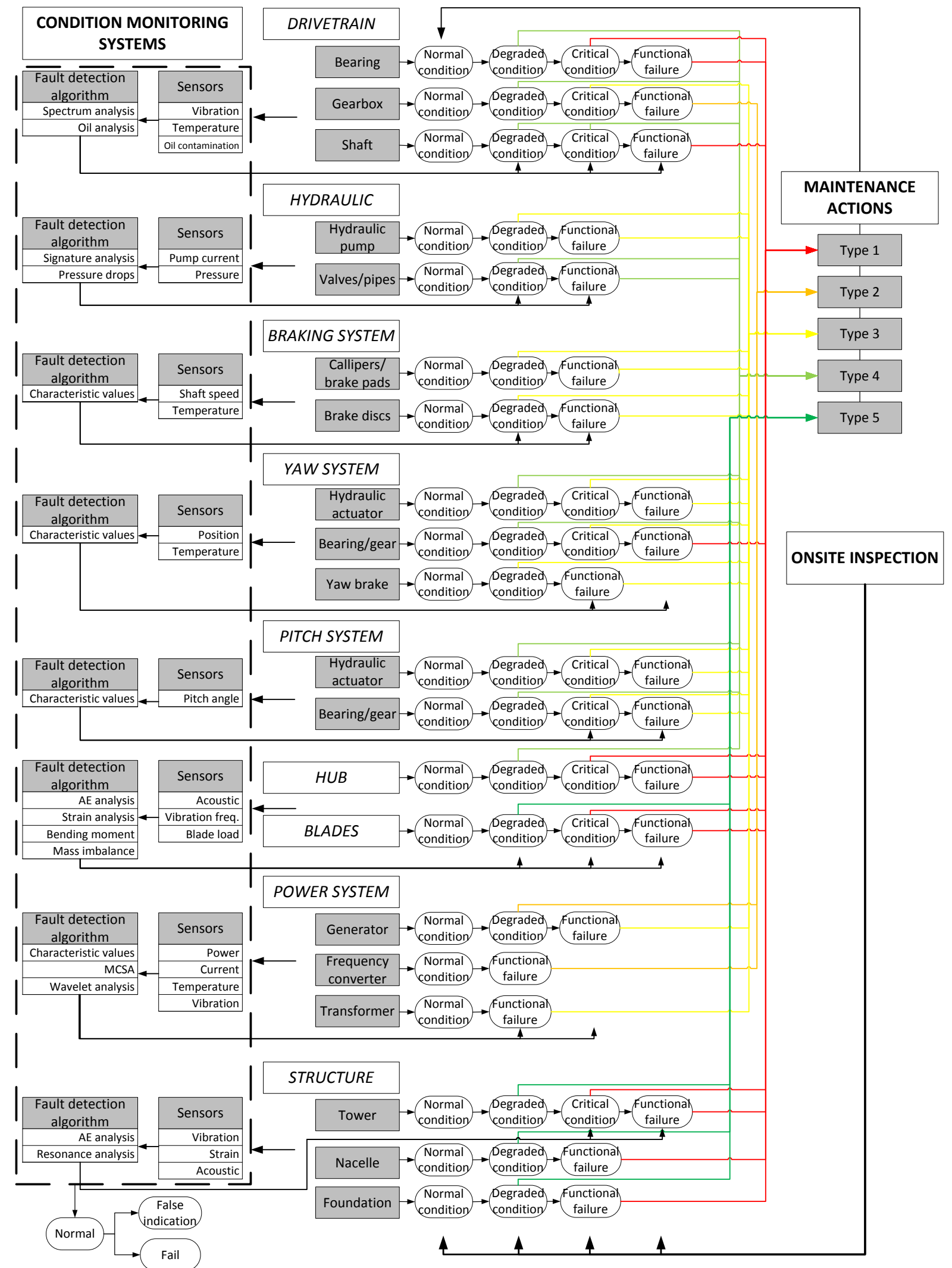

Figure 3: Asset state model 


\subsection{Maintenance categories}

\begin{tabular}{|c|l|}
\hline Type & \multicolumn{1}{|c|}{ Description } \\
\hline 1 & Heavy component, requires external crane. \\
\hline 2 & Heavy component, requires internal/external crane $(>800-1000 \mathrm{~kg})$. \\
\hline 3 & Small parts, requires internal crane $(<800-1000 \mathrm{~kg})$. \\
\hline 4 & Small parts, inside nacelle. \\
\hline 5 & Small parts, outside nacelle. \\
\hline
\end{tabular}

Table 1: Maintenance category

Depending on the wind turbine components and their condition, different maintenance action is required. For offshore wind turbines, maintenance is difficult and requires a lot of planning and support. In this paper, these maintenance actions are distinguished mainly due to the size of the components and the required supporting equipment. There are 5 maintenance types considered as shown in Table 1, they are adopted from the current maintenance categories used in the industry $[28,29]$. Type 1 contains all types of maintenance which require the lifting of heavy and large components, for this purpose, a large crane on a jack-up vessel is required. Examples of this requirement are the replacement of the blades or the rotor. Type 2 is maintenance which requires the lifting of heavy and large component that usually requires the use of the internal crane [30]. This type of maintenance often deals with heavy components inside the nacelle such as the gearbox, generator, and transformer. Type 3 is the maintenance which requires the normal lifting service of the internal crane, these parts cannot be carried manually. Examples of this category of repairs are the replacement of the pitch or yaw motor/actuator. Maintenance type 4 and type 5 contain all other types of maintenance, the components and equipment can be man carried. The only difference between types 4 and 5 is that, type 4 is all the work inside nacelle which is considered a controlled and safe working environment, whereas type 5 is the work outside the nacelle and the tower (e.g. patching, sealing, loss of sections repair on the blades; corrosion repair and repainting on the outside of the towers and nacelle). The appropriate maintenance types and repair actions at different degraded states for all components have been illustrated in Figure 3 and are also tabulated in Table A1, the Appendix.

\section{Petri net model for the wind turbine asset}

In this section, the development of the complete wind turbine maintenance model based on the Petri net approach is presented. The system level model is built from modules, each module models different processes for a sub-system and its components. The complete model is formed by linking these modules together.

\subsection{Petri net method}

A Petri net (PN) [31] is a directed bipartite graph with two types of nodes, places and transitions and they are linked by arcs. Arcs connect places to a transition and indicate the input places of the transition, and arcs from a transition to places indicate the output places of the transition. Places, denoted by a circle, represent a particular event or state of the system. Transitions, denoted by a rectangle, enable the system to change state and thus model the dynamic 
behaviour of the system. In this paper, places can be used to indicate the condition of the wind turbine components and the dynamic processes such as the deterioration, inspection and maintenance are represented by the transitions. Tokens, denoted by a dot, are added to places and the marking of tokens in places within the net indicate the current system state. The movement of the tokens between places is by the firing of the transitions, and this firing process can only happen when the transition is enabled. In a basic PN method, an enabled transition requires a token to be present in all of its input places, after the firing process, the appropriate number of tokens in the input places is cleared and the appropriate number of tokens is deposited in the transition output places. When the firing happens immediately, it is called instant transition. When the firing happens after a time $t$, it is called a delayed transition. In this case, the delay time $t$ can be sampled from an appropriate distribution.
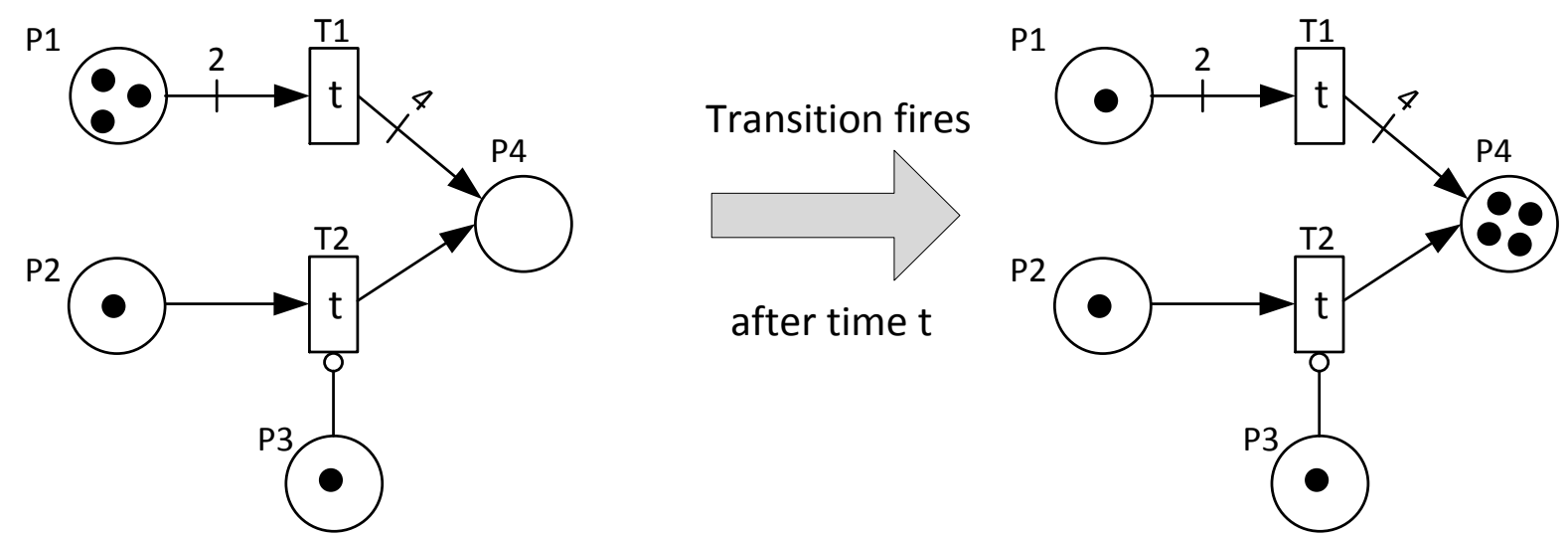

Figure 4: Simple PN with arc multiplication and inhibitor arc and the firing process.

A simple PN is illustrated in Figure 4. The positive integer associated to an arc is called the multiplicity [32]. If the arc is an input arc from a place to a transition then the multiplicity dictates the number of tokens needed for the transition to be enabled. If the arc is an output arc from a transition to a place, the arc multiplicity indicates the number of tokens that will be deposited in the output places. An inhibitor arc [33] can only go from a place to a transition and is denoted as an arc with a round end. When the input place P3 is marked with a token, the transition T2 is inhibited and will not fire as long as the token remains in place P3. This is the reason why after time $\mathrm{t}$, the token in place $\mathrm{P} 2$ remains as the transition $\mathrm{T} 2$ is inhibited from firing by a token in place P3. The inhibitor arc may also have a multiplicity, in this case, the place must contain at least the number of tokens as indicated by the arc multiplicity for the transition to be inhibited.
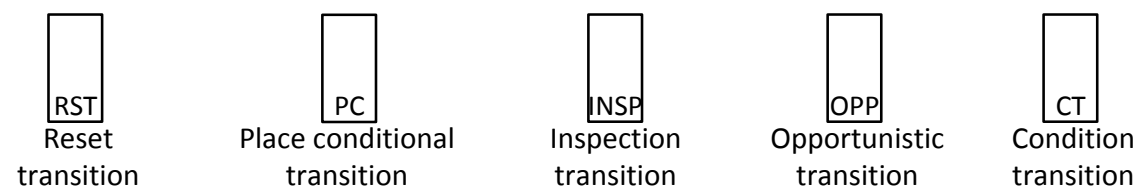

Figure 5: Representation of special transitions

In addition to the traditional PN features, new types of transitions (Figure 5) are used in this paper to accommodate certain tasks to produce an efficient model. A reset transition [34], when it fires, resets the marking of specified places in the PN to the desired number of tokens. This feature is useful for when maintenance action has happened and component condition is 
restored. A place conditional transition [35] is a transition in which the delay time is sampled from different distributions depending on the number of tokens residing in a specific place in the network to which they are linked by a dashed arc. This transition allows easy modelling of dependent deterioration processes. An inspection transition [36] only fires when the system time is at a specific time. This transition is used to model the inspection process where the component condition is revealed after a specified time interval. An opportunistic transition [36] is used in the modelling of opportunistic maintenance action and each component is modelled by different types/colours of token. Opportunistic maintenance is applicable when the condition of a component to be maintained permits work to be carried out on a component yet to reach this condition. A condition transition deposits the token in only one of its output places according to a set probability. This feature is used when malfunctioning condition monitoring systems (CMSs) could falsely indicate the component condition i.e. the revealed condition could be better or worse that the true condition.

\subsection{Petri net for modelling the degradation process}

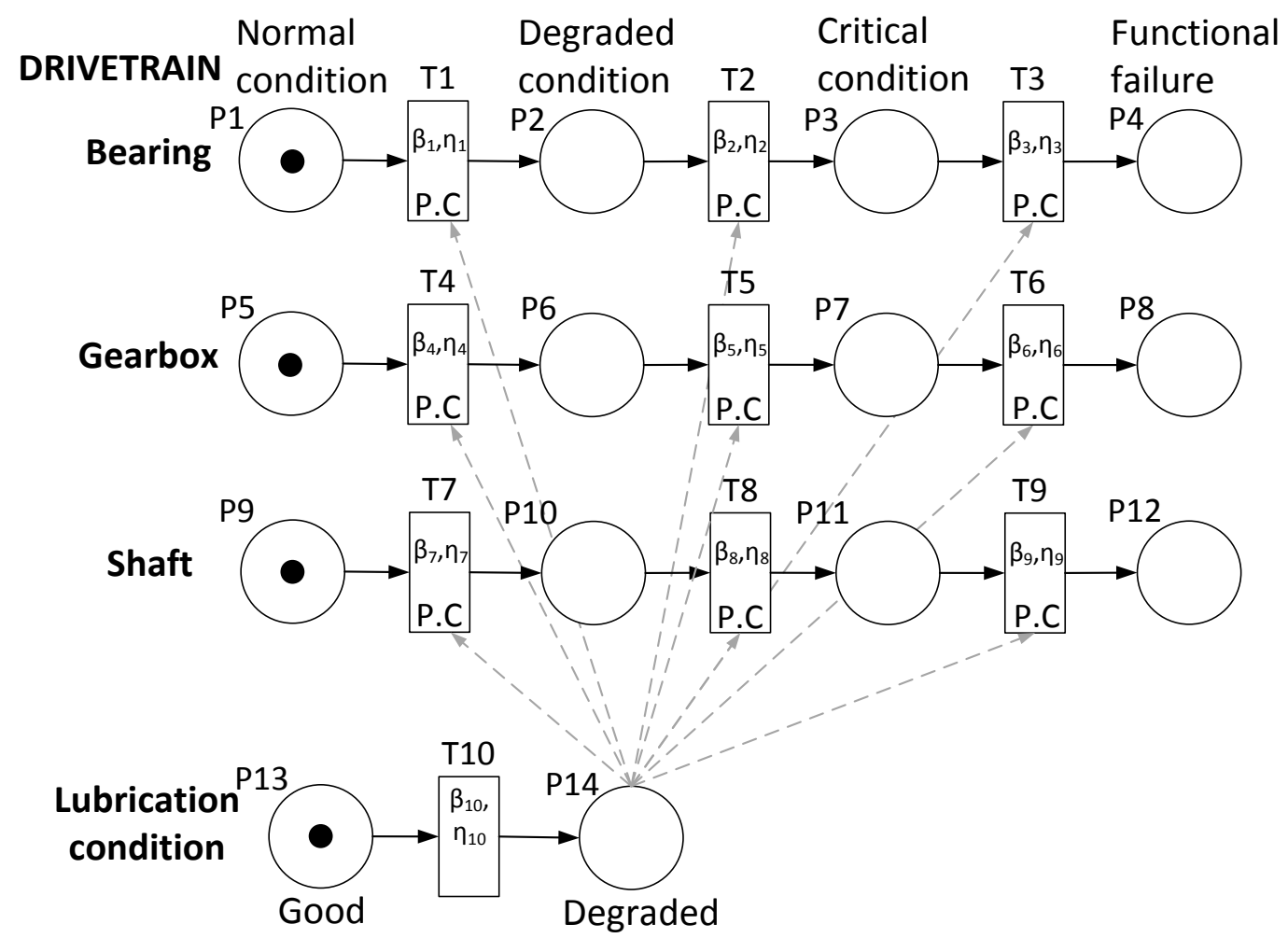

Figure 6: PN for the degradation process of the drivetrain system.

Figure 6 illustrates the PN modelling the condition degradation process of the drivetrain components. The component states are represented by places P1 to P12. The degradation processes between these states are represented by transitions T1 to T9. These transitions govern the transition times between the condition states, and follow specific distribution functions which statistically model the degradation characteristics of a component. The failure characteristic of the drivetrain components has an increasing failure rate over time as damage accumulates [14], this is accommodated in the model by using the appropriate distribution. In particular, the transition times follow a Weibull distribution with parameters $\left(\beta_{\mathrm{i}}, \eta_{\mathrm{i}}\right)$ for each transition $i$. Places P13 and P14 represent the good and the degraded state of the drivetrain 
lubrication oil, and transition T10 represents the degradation process between these states. The condition of the lubrication has a significant effect on the degradation process of the drivetrain system [13] and this is taken into account in the modelling performed in this paper. As the lubrication condition degrades, this has effects on the degradation processes of the drivetrain components. The effect is captured in the net with the use of place condition transitions (marked with P.C). With these transitions, the transition times are dependent upon the marking of token in place P14. Therefore, when P14 is marked, the transition times governed by transitions T19 are sampled from the appropriate distributions so that it reflects the degradation of the drivetrain components when the lubrication oil has degraded. For other wind turbine subsystems and their components (Figure 3), the PNs modules modelling the degradation processes follow similar structure.

\subsection{Petri net for modelling the condition monitoring and inspection process}

\section{Inspection process}

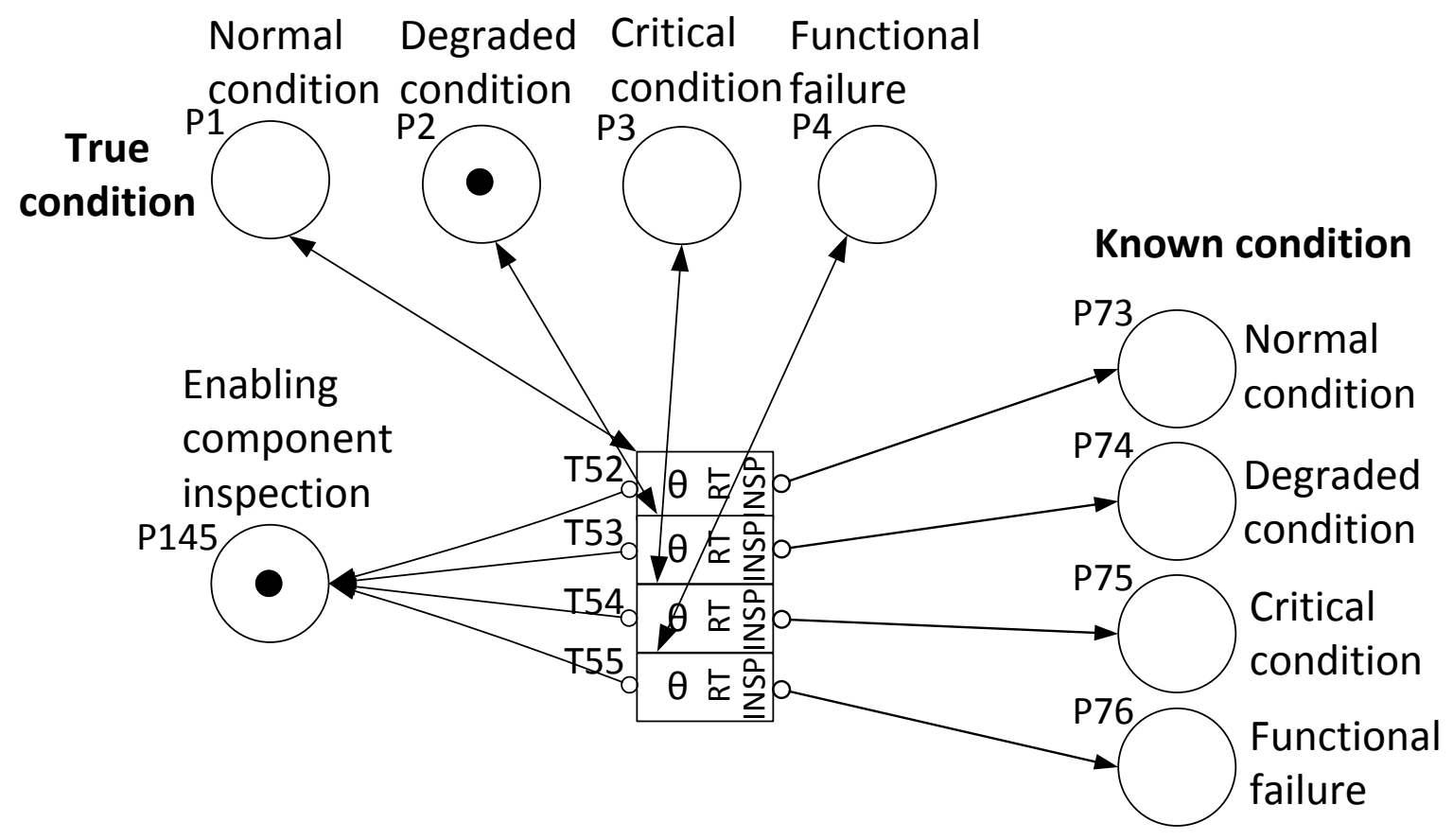

Figure 7: PN for the inspection process

Inspection of wind turbine items is typically performed around every 6 months or every year. This process is modelled using the inspection transitions as illustrated in the net in Figure 7. For a component with four condition states as represented by P1-4, the firing of transitions T52-55 will deposit a token into places P73-76 as appropriate. This is the process by which the condition state is revealed following an inspection. The reset properties in transitions T52-55 also ensure that the previous known condition, obtained at the last inspection or from the last reading of the condition monitoring system is updated to the current condition. The net also allows the deterioration process to continue after the inspection process has revealed the component condition at that time. This section of the net is then repeated for all components.

\section{Condition monitoring process}


Beside onsite inspection which is periodical, condition monitoring systems (CMS) are employed in some parts of the wind turbine to continuously monitor the component conditions. This continuous monitoring process reveals changes in the system state immediately. The PN module that models the process is illustrated in Figure 8. When the CMS is in the normal working condition, any changes in the component's true condition is immediately updated by the firing of transitions T124-127 and the token is deposited into P73-76 to reveal the new component's known condition. These transitions have zero firing time i.e. instant transitions. They also have the reset (RT) property so that when they fire, any token in places P73-76 would be cleared before the depositing of the token action to represent the new known condition is updated.

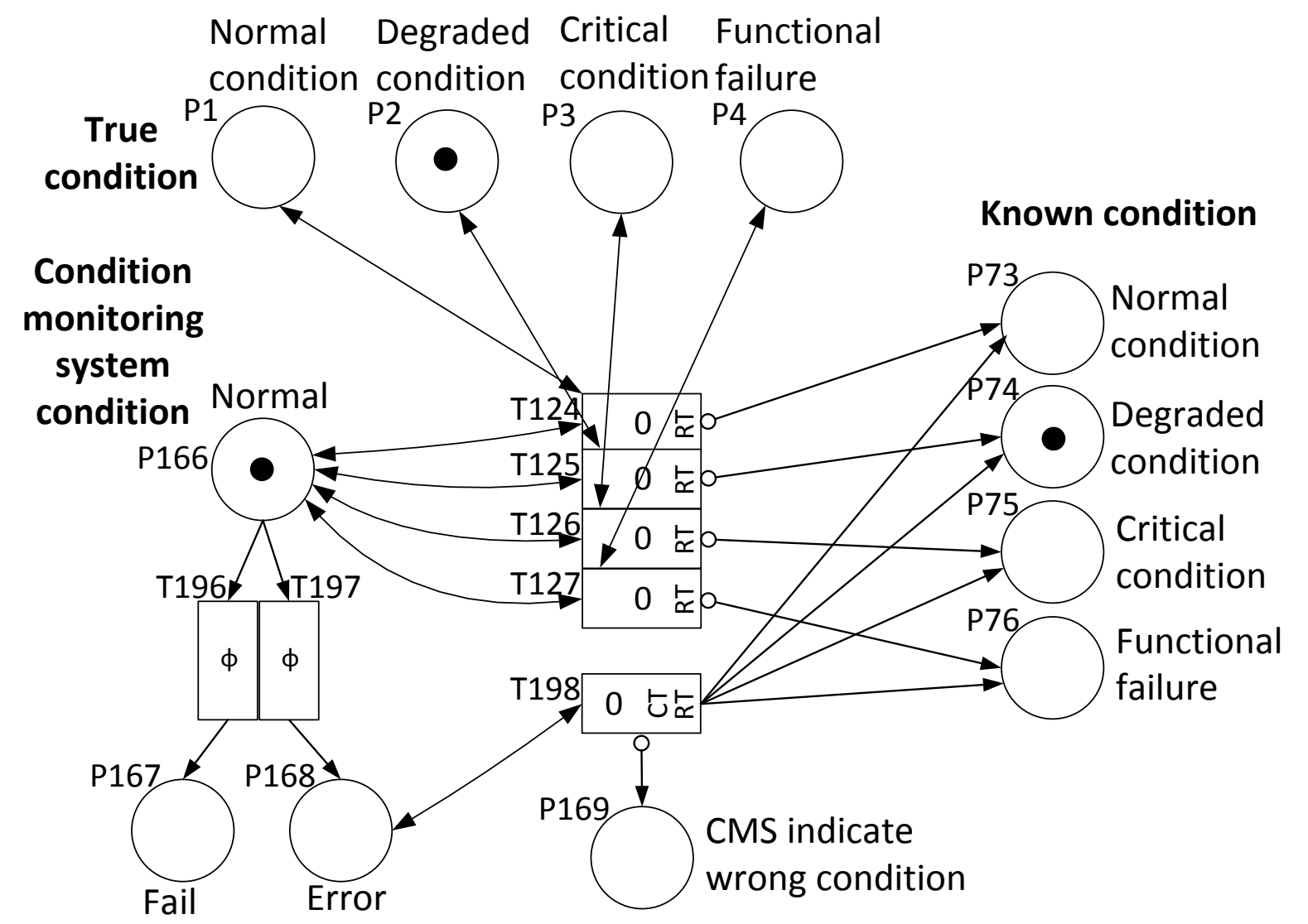

Figure 8: PN for the condition monitoring process

The CMS is also subject to failure and error, these states are presented by places P167 and P168 respectively. When transition T196 fires, the token is removed from P166 and deposited in P167, this means the CMS has failed. When this happens the component is no longer continuously monitored and the component known condition remains the last known condition before the CMS failure. It is assumed that the CMS condition is checked following onsite inspection and its condition is restored to the normal condition if it is found to be in the malfunction or failed condition. When the CMS is in the error state, the component known condition might be wrong i.e. different from the true condition. Transition T198 has the conditional property (marked by CT) so that when it fires, a token is deposited into one of its output places (P73-P76) according to a set probability. This feature models the process in which a malfunctioning CMS could falsely reveal the component condition that could be either better 
or worse than the true component condition. This net structure is applied to other wind turbine components whose condition states are monitored by condition monitoring systems.

\subsection{Petri net for modelling the maintenance process}

\section{Enabling correct maintenance actions}

Figure 9 illustrates the part of the net that models the enabling of the necessary maintenance process after an inspection. When the maintenance is enabled, the marking of places P250 and P251 indicates that the component now requires repair and the type of repair that is required. The arc multiplicities connecting T259-261 to P251 indicate the number of tokens in P251 which corresponds to the maintenance categories presented in Table 1, e.g. 4 tokens means the component requires type 4 maintenance action. One important feature of the net is that maintenance actions are based on true component condition. This is critical since the CMS may indicate the wrong condition or the component might have deteriorated to a worse condition whilst awaiting repair. This is modelled by the marking of P252 which is when the actual repair begins, the marking of $\mathrm{P} 251$ will be updated accordingly to the component true condition with the firing of transitions T310-313.

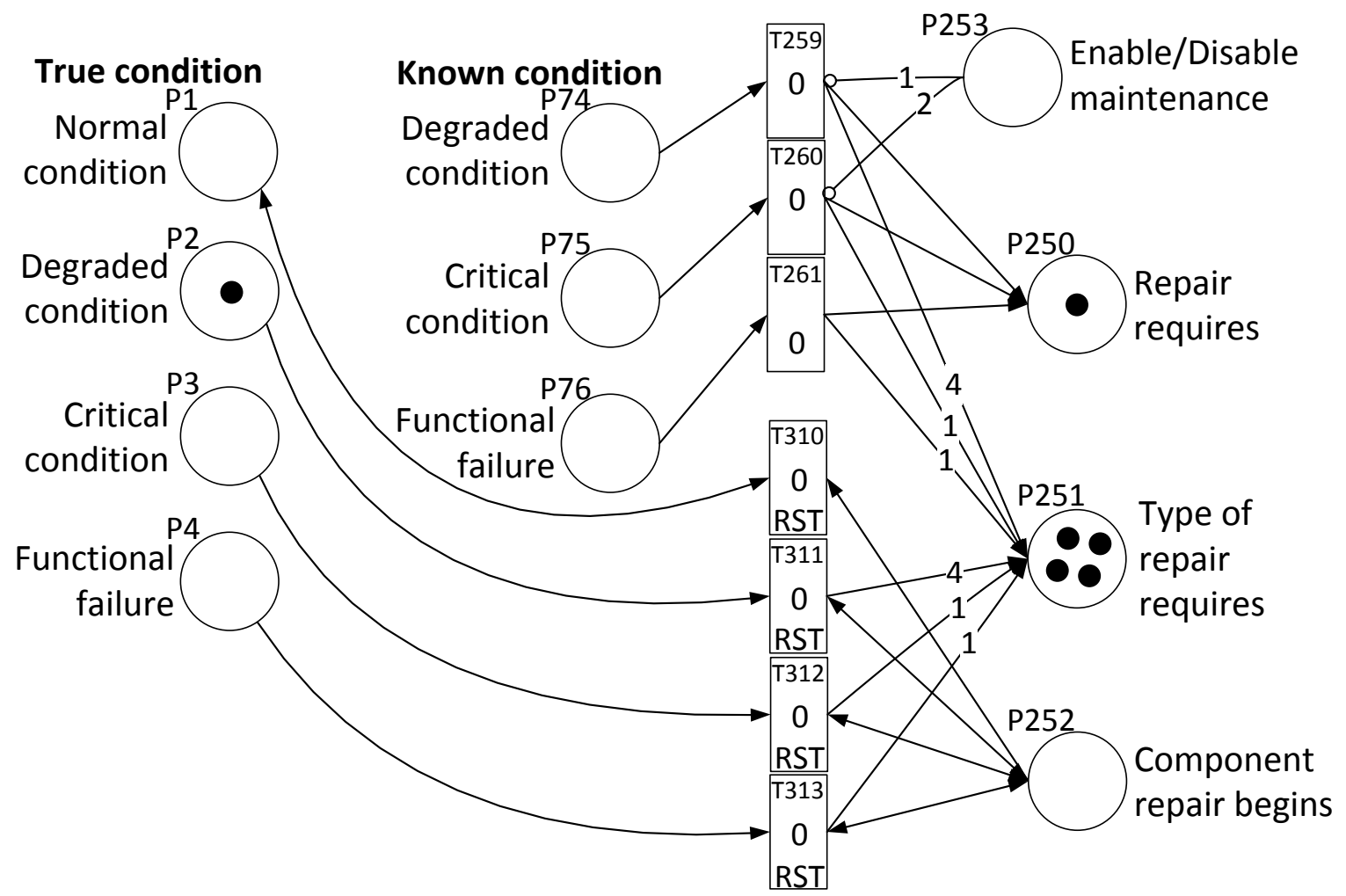

Figure 9: PN for enabling the maintenance actions for a component

\section{Maintenance strategy and opportunistic maintenance}

Different maintenance strategies can be implemented (turned on or off) in the model by placing the correct number of tokens in place P253 in Figure 9. Effectively, the appropriate number of tokens sets the degraded component condition that will trigger maintenance. For example, with 1 token in P253, the component will be maintained as soon as it reaches the critical condition. 
The option for degradation levels which trigger maintenance is set for each component individually.

Opportunistic maintenance is also implemented in the model. Opportunistic maintenance is applicable when the condition of a wind turbine component to be maintained permits work to be carried out on another component yet to reach this condition. To efficiently model the opportunistic maintenance process, a special transition (marked with OPP) is used. The net for this process was presented and discussed in [36]. Opportunistic maintenance triggers the repair process for a component in a deteriorated condition but would not normally trigger maintenance. This is process is modelled by placing tokens into the places indicate repair is required for the components (e.g. depositing a token into P250 in Figure 9). The opportunistic transitions are instantaneous to ensure that opportunistic maintenance is implemented when the maintenance process starts.

\section{Maintenance process}

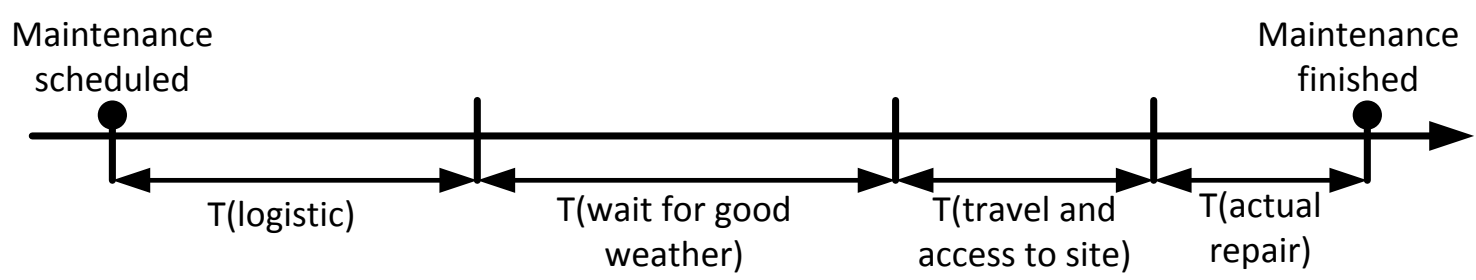

Figure 10: Composition of the repair process

The maintenance process starts once the repair actions are determined and the process includes the key stages: planning/logistics, waiting time for a good weather window, travelling and access to site, and actual repair time as shown in Figure 10. The planning time includes the time to order spare parts, arrange technicians, tools and transport means. Whilst the logistic time and repair time are dependent upon the specific component and the severity of failure, the waiting time for a good weather and the travelling/access to site are a common factor for the whole wind turbine. Figure 11 shows the PN for the maintenance process that applies to each component. The net ensures that each component would have appropriate logistic and repair times, whilst the waiting time and the mission time (travel/access) are common for the whole asset. The maintenance process only starts after the longest logistic time has elapsed so that all the replacement parts and equipment are ready before the maintenance crew perform the works. Once the repair has been carried out, the restored component conditions are represented by placing tokens into places P1 and P70. This part of the net for modelling the performance of the maintenance process is linked with the PN for enabling the maintenance action (Figure 9) using the common place P252. This completes the maintenance process model for a wind turbine. 


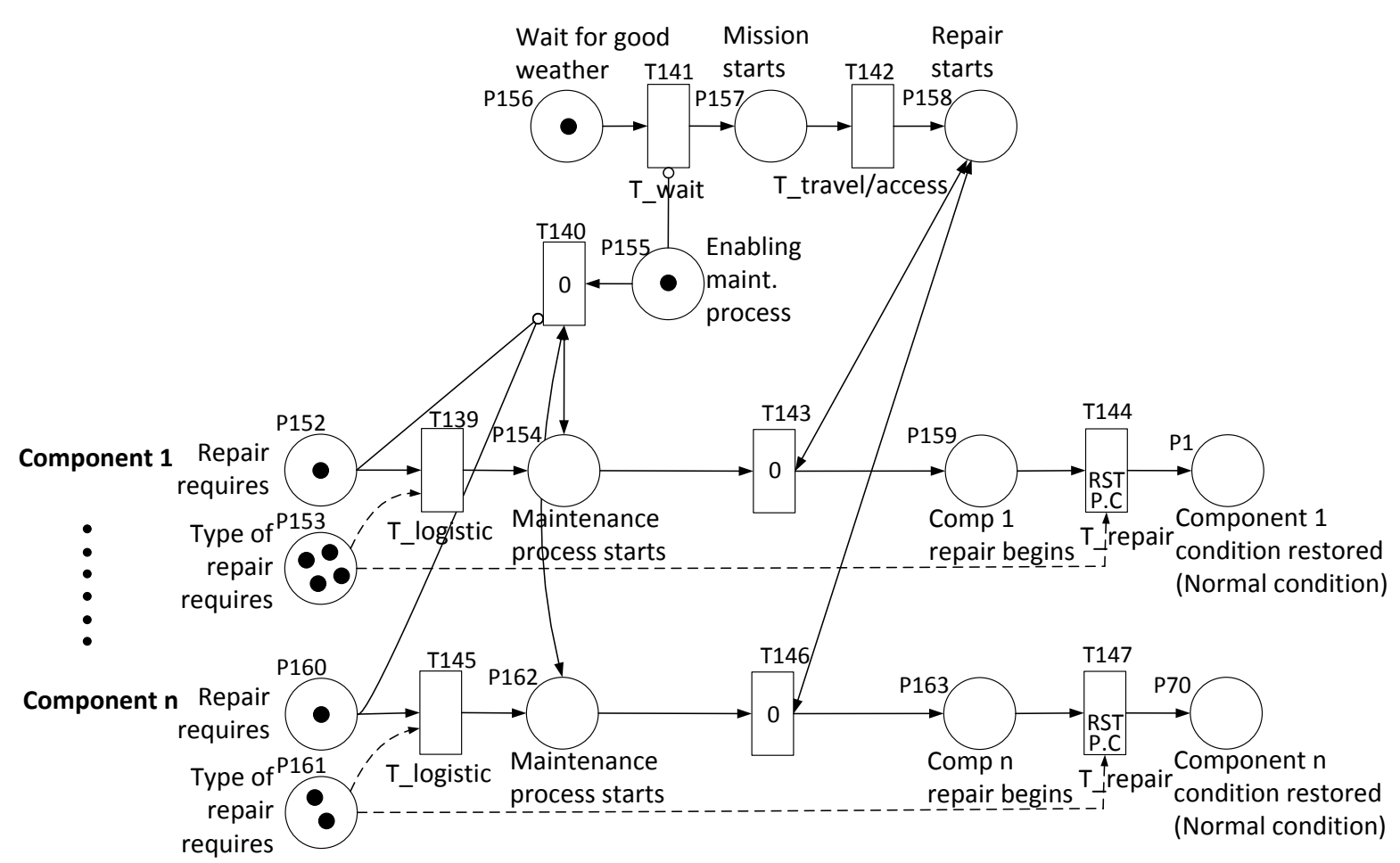

Figure 11: PN for the maintenance process of a wind turbine

\section{Model results and discussions}

The PN model provides a simulation frame work for all the stochastic processes considered. The wind turbine PN is then solved using the Monte Carlo simulation [37]. The transition times in the model are generated by random samplings [34] from the appropriate Weibull distributions. A computer program was written to accommodate the generation and solution of the developed PN model. The model could be used to illustrate a maintenance strategy required to operate the wind turbine over a specified lifetime. In this section, the model is simulated to predict the wind turbine condition over a 40 year life period. As the number of simulations increases, statistics are collected to allow the investigation of relevant metrics, including the probability of the asset being in any of the condition states, the expected number of interventions and associated costs and future asset condition profile under a specific maintenance strategy. In this section all the wind turbine components are assumed to be in the good, working, condition initially, and maintenance actions restore the condition of a component to this condition. In the results given the maintenance strategy that has been assumed is to carry out maintenance as soon as any component deterioration is revealed. Other maintenance strategies can be applied however the results are not presented.

The model inputs are given in Table A2, A3 the appendix. The parameters of the input degradation distributions of the wind turbine components are estimated using failure information provided in a number of studies in the literature, these failure parameters are therefore indicative. In order to obtain good Weilbull parameters for a particular wind farm, the parameters can be estimated using the condition data recorded for wind turbines in the particular wind farm. Along with condition data, historical repairs, costs and 
logistic/travel/access/repair times can also be gathered for the Weibull distribution parameters estimation. In the case of limited data, estimation using data from similar wind turbine types operating under similar conditions combining with expert knowledge would also give a good estimation. Initial estimates could be updated using Bayesian methods as the more representative data collected from this wind farm became available. In many studies, the weather waiting time, before maintenance can take place, is often expressed as a function of the wave height and maximum wind speed that the maintenance support vessels can operate under. However, for simplicity, the model developed in this paper assumes a distribution that governs the weather delay times.

There are three key performance statistics that are presented in this section as described below. These statistics are obtained for each component (component analysis) and can be combined to give the performance of the whole system (system analysis).

1. Condition prediction: the probability or the time a component residing in any condition state.

2. Failure prediction:

○ The average number of component failures over the system life time

- The number of early component replacements prior to their failure

- The distribution of the wind turbine or the component downtimes

- The contribution of all components to the total system downtime

3. Maintenance prediction:

○ The number of repairs required given a specific maintenance strategy

- The maintenance costs given a specific maintenance strategy

- The number of site visits for maintenance and the number of vessels required

\subsection{Component analysis}

\subsubsection{Component condition prediction}

Figure 12 shows the probabilities of the drivetrain gearbox being in the different condition states over the 40 years prediction period. The expected probability of the gearbox being in a normal condition is just above 0.8 , less than 0.2 of being in a degraded condition and it is very unlikely to be in a critical or a failed condition. With a maintenance strategy which conducts repair as soon as component deterioration is detected, it is likely the gearbox will be operating in its normal condition over its lifetime. 


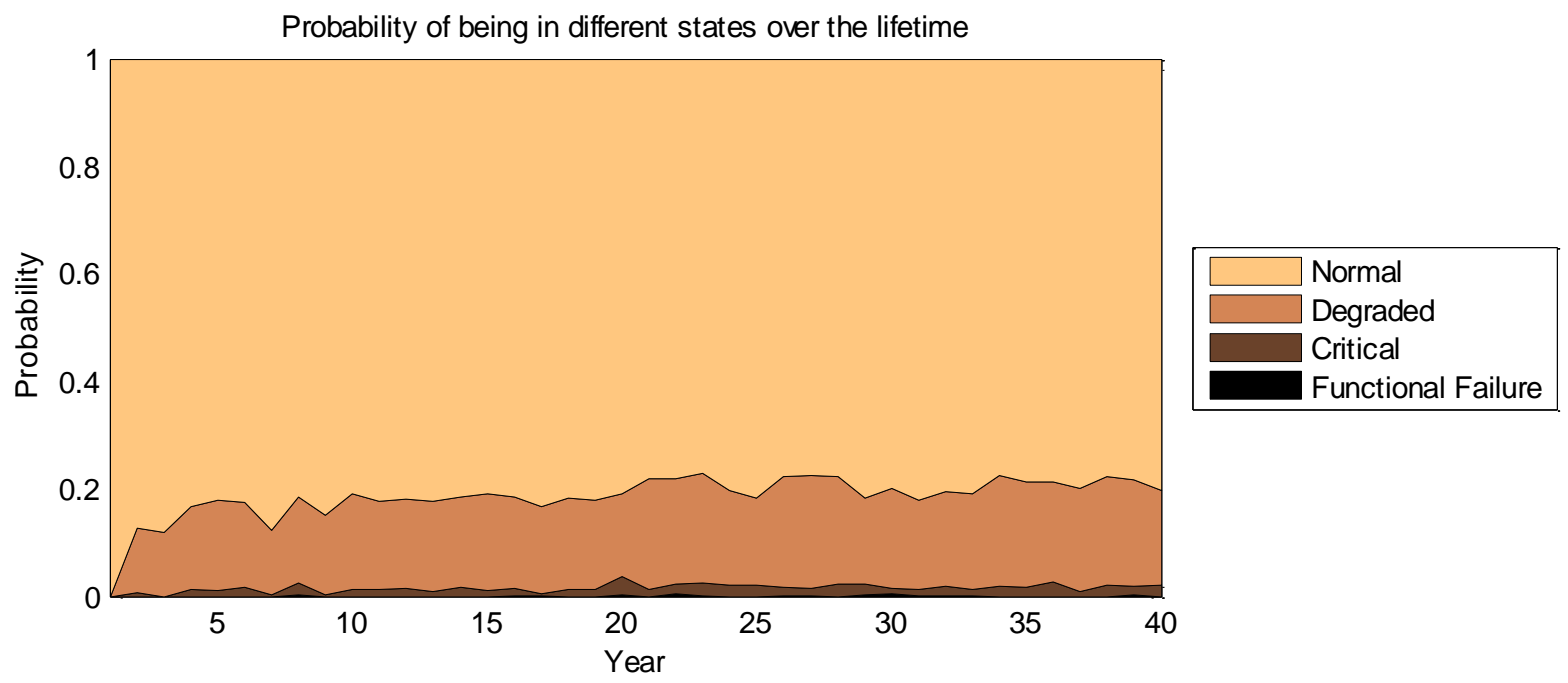

Figure 12: Probabilities of the drivetrain gearbox being in different condition states over the simulated life time

\subsubsection{Component maintenance prediction}

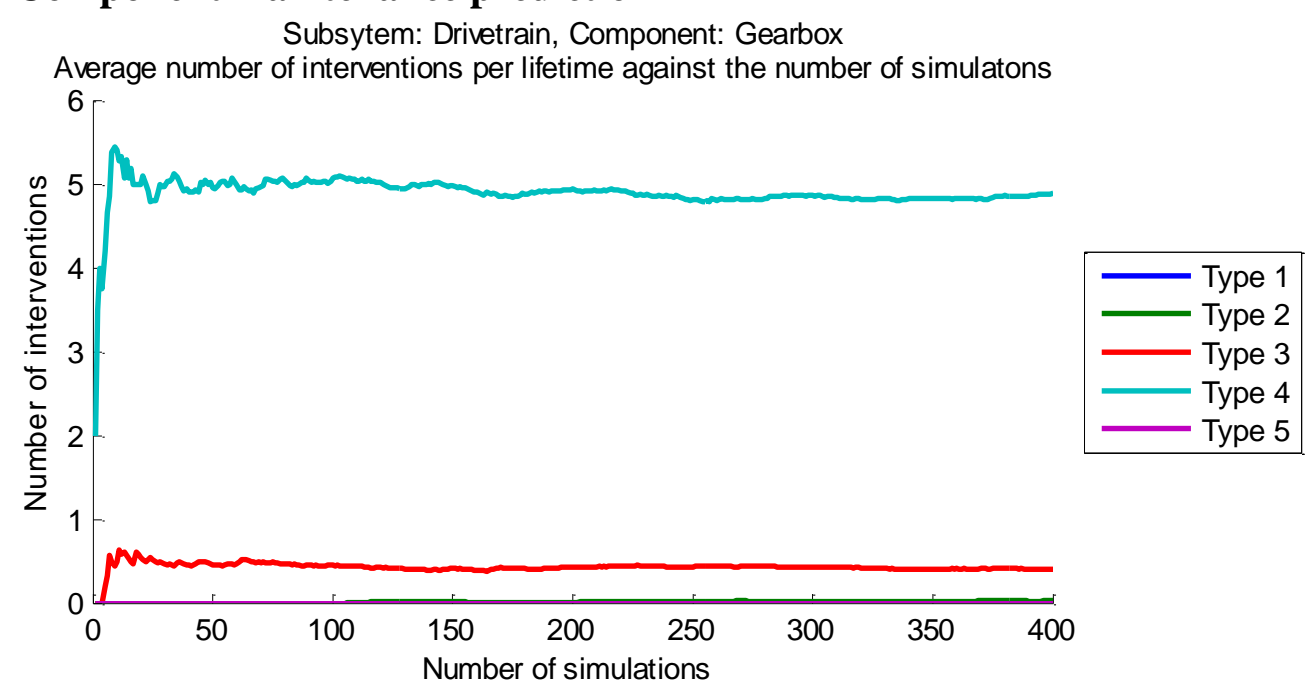

Figure 13: Average number of repairs on the drivetrain gearbox over 40 years period

Figure 13 plots the average number of repairs on the drivetrain gearbox over its lifetime. As discussed in previous sections, three types of repairs are considered on the gearbox: type $4-$ small part repairs inside the nacelle; type 3 - small part repairs which require the internal crane; and type 2 - heavy component repairs which require the internal crane. The expected number of repairs over 40 years prediction period for type 4 maintenance is around 5 times, for type 3 is 0.4 times and nothing for type 2. This shows that, with this maintenance strategy, it is expecting to carry out gear tooth repairs (type 4) about 5 times, however there would be no gearbox replacement (type 2). The plot also shows that the results convergence is found prior to 400 simulations. 


\subsection{System analysis}

\subsubsection{System condition prediction}

By combining the results for component performances, the system performance can be predicted. Assuming all components are of equal importance, Figure 14 shows the probabilities of the wind turbine being in different condition states over 40 years prediction period. The effect of the chosen maintenance strategy is clearly demonstrated with a very high probability that the asset will be operating in a normal condition. The probability of the wind turbine reaches the failure state due to any of its components' failures is around $4 \%$ at every year.

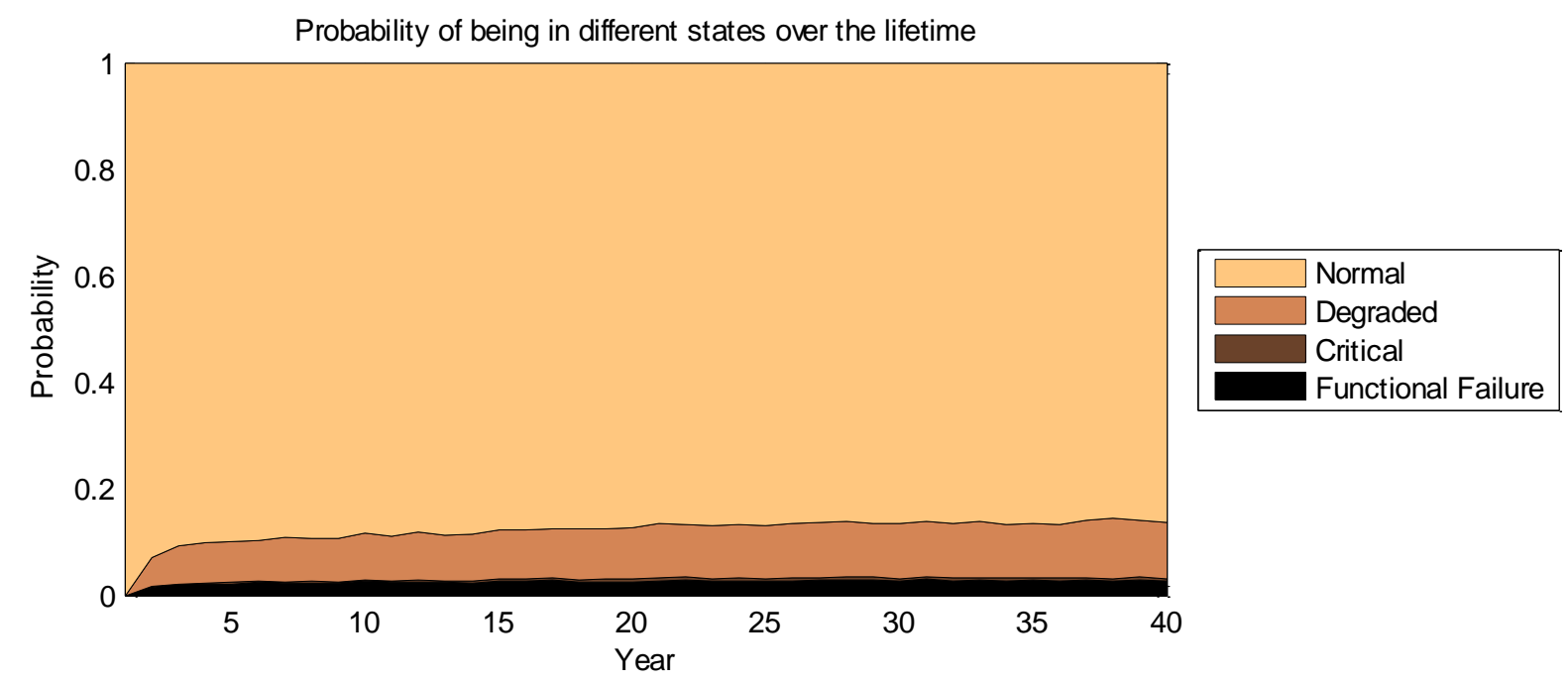

Figure 14: Probability of the wind turbine being in different condition states over the simulated life time

\subsubsection{System failure prediction}

By tracking the number of times a component reaches the failed states in the PN model, the average number of failures for all components over their simulated lives can be shown as illustrated in Figure 15. The number of failures of the power generation system clearly contributes the most to the failure of the whole wind turbine where more than 10 are failures are expected over the 40 years for the frequency converter and the transformer. The reason why other components are expecting much less failures is because of the use of CMSs. With the CMS, component condition is continuously monitored, repair is carried out as soon as the component condition has degraded, thus reducing the probability of component failure. In contrast, the CMS is not applicable on electrical systems thus there is a higher number of failures due to electrical equipment. 


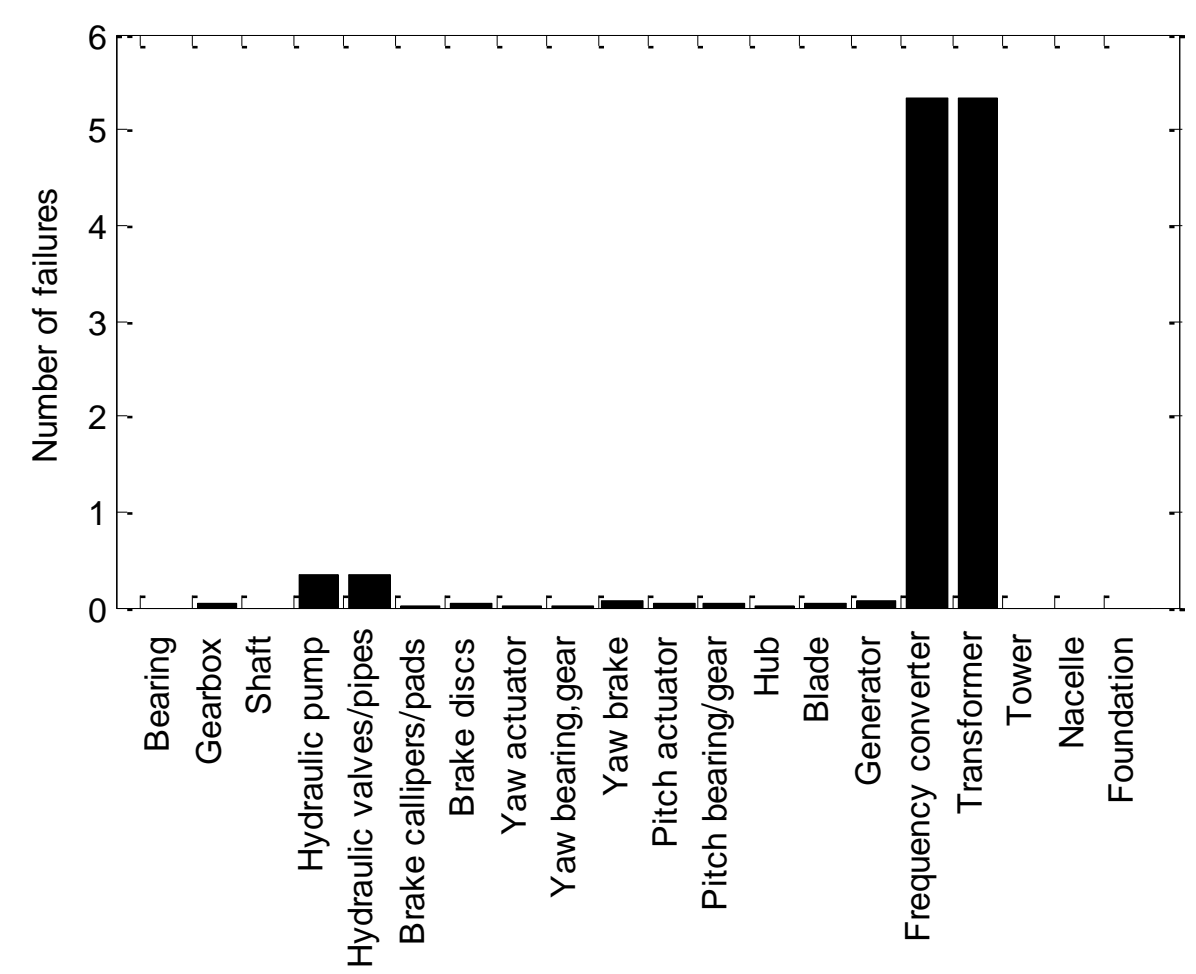

Figure 15: Average number of component failures over its lifetime.

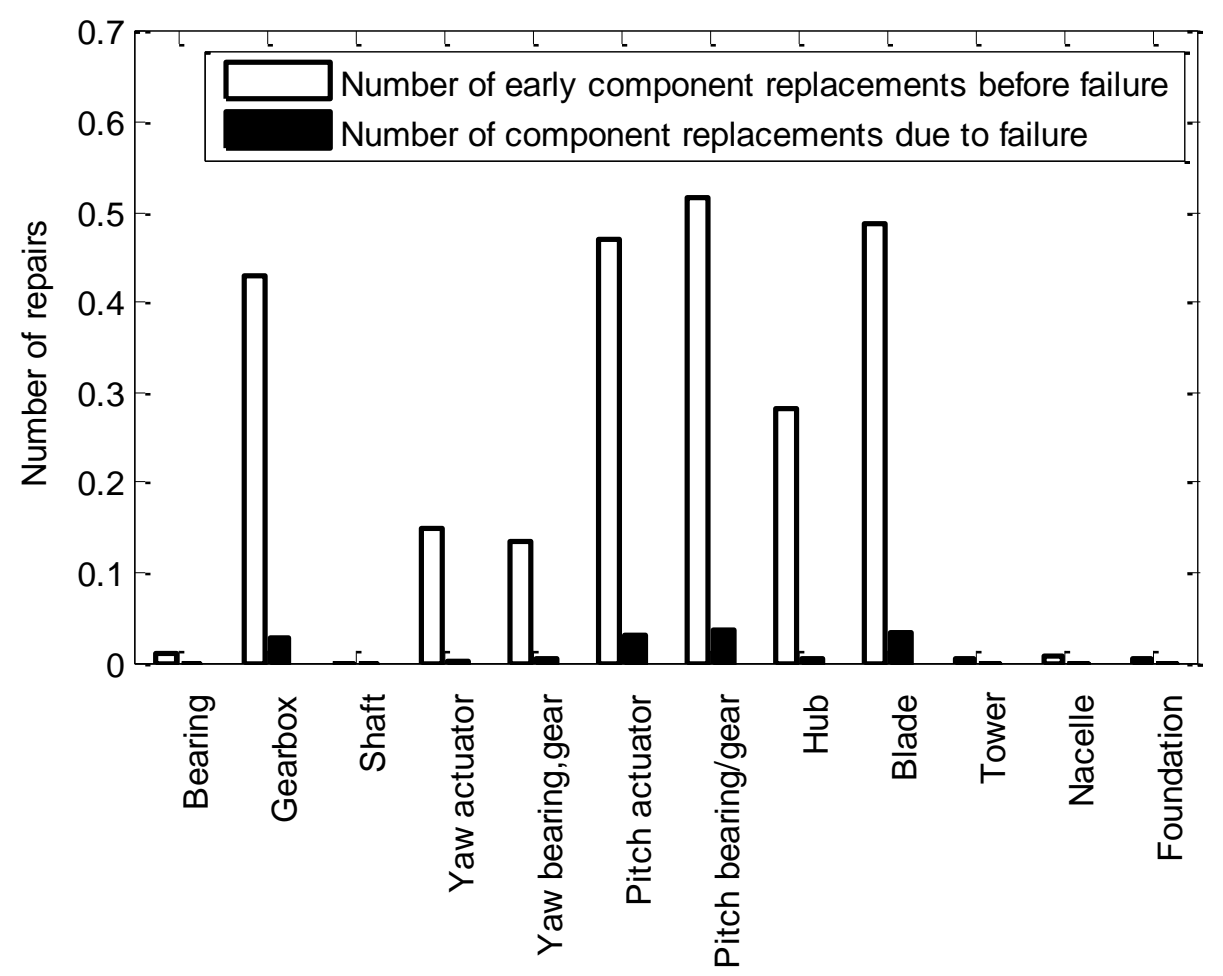

Figure 16: Average number of component replacements prior to failure.

The key feature of the condition monitoring systems is the early failure indication so that an early component repair or replacement can be made to minimise service disruption. Figure 16 shows the number of early repairs/replacements for components on which the CMSs are installed. It can be seen that, as expected, the number of preventive component replacements are significantly higher that the number of component replacements due to failure. This indicates that a significant number of component failures is prevented with the use of the CMS 
and the early replacement maintenance strategy. The average number of early component replacements is calculated by tracking the average number of times that a component is repaired/replaced when it is in the critical condition. The number of component replacements due to failures is the same as the number of component failures as shown in Figure 15, this is because the component is always replaced when it fails.

By tracking the times a token resides in a particular state, the distribution of times for which a component, or the entire system, is predicted to be in any condition state can be obtained. Figure 17 shows the distribution of times that the wind turbine resides in the failed condition, in other words, the figure shows the distribution of wind turbine downtimes. The wind turbine downtime is a function of the time until when the failure is revealed, the logistic time to prepare parts and equipment, the time to wait for a good weather window, the time to travel/access to site and the actual repair and despatch time. The distribution obtained shows that $90 \%$ of time, the wind turbine downtime is less than 31.3 days. This information is useful to estimate the energy production loss due to component failures. The key difference between the model presented in the paper and other probabilistic models available is that the downtime is explicitly expressed as a function of the time when the component failed until its condition is revealed, the logistic time to prepare parts and equipment, the time to wait for good weather window, the time to travel/access to site and the actual repair and despatch time. In contrast, this level of details is not captured in other models, instead the wind turbine downtime is often a linear relationship with the number of wind turbine component failures. Effectively, the PN model presents the downtime results as a distribution of times and the results can be analysed further at component level. For other models, the results often only present an average downtime.

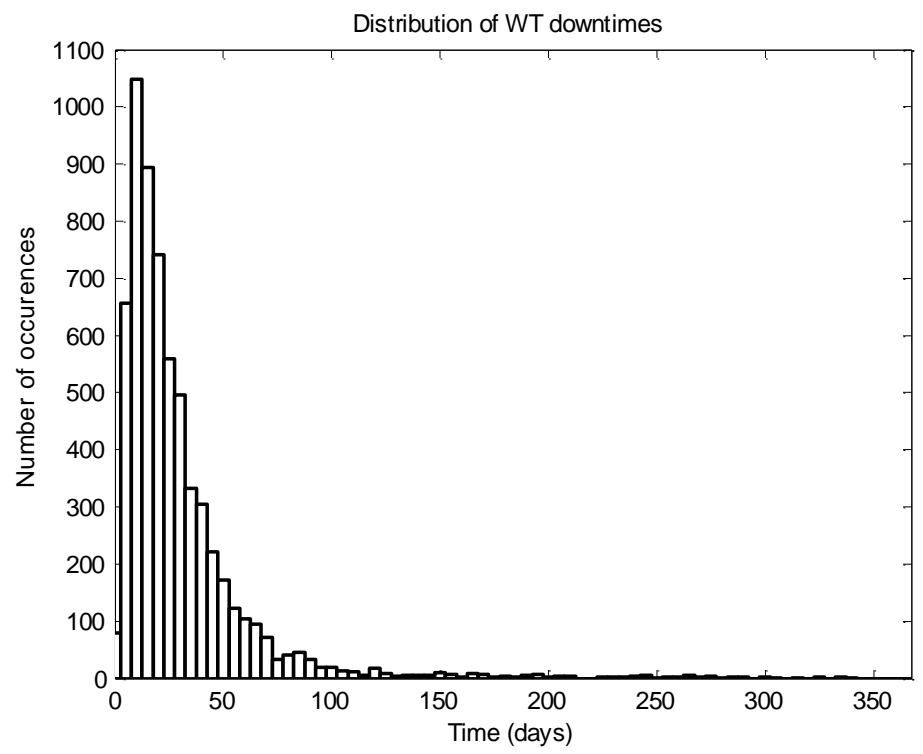

Figure 17: Distribution of wind turbine downtimes

Considering the wind turbine downtimes, shown in Figure 18, they can be broken down according to the failed components which caused the system failures. Figure 18 shows the contribution of the component failures to the auxiliary sub system downtime. The auxiliary system comprises of the hydraulic, pitch, yaw and braking systems and this subsystem is chosen for this analysis because it better demonstrates the results obtained rather than including 
other components such as the structure tower, nacelle and foundation where their contributions to the wind turbine down time are almost negligible. Figure 18 clearly shows that the hydraulic system has the longest failure duration compared with other systems. This agrees with the fact that the hydraulic system powers the other three systems (yaw, pitch and brake) thus it is more likely to fail and often contributes to the longest down time in the auxiliary system.

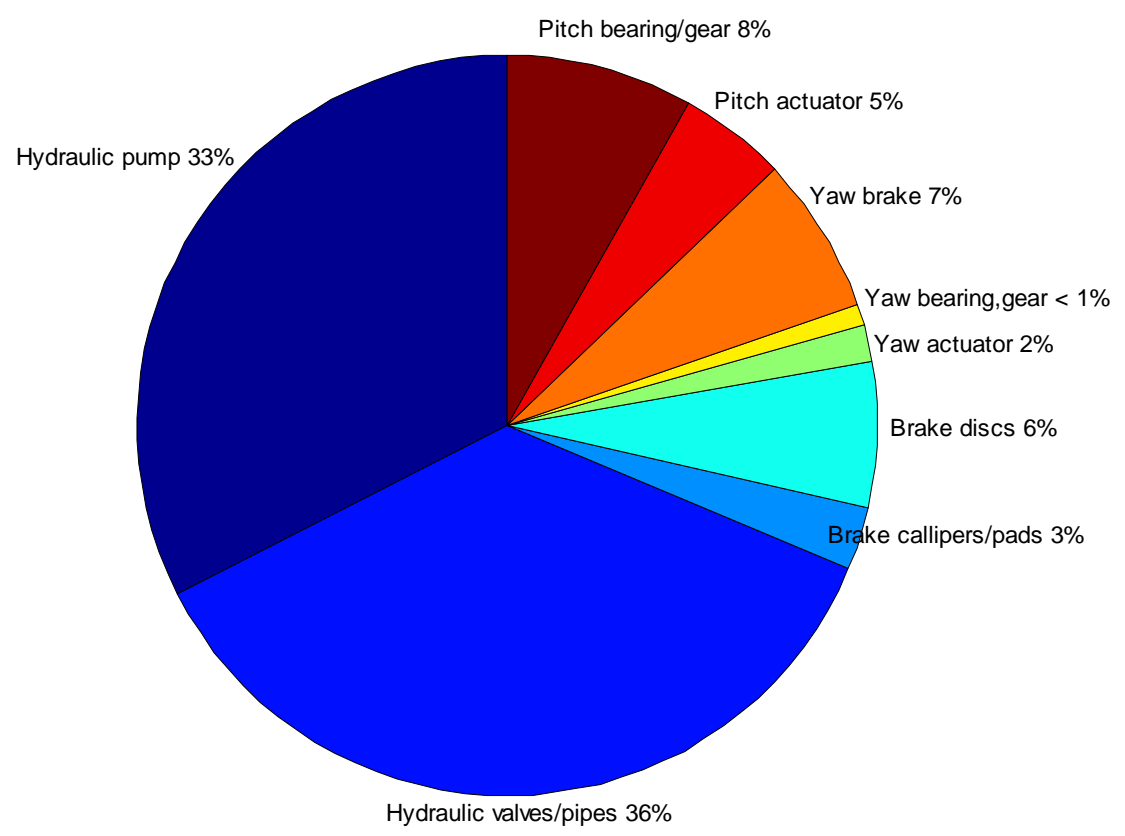

Figure 18: Contribution component failure to the downtime of the auxiliary system (hydraulic, pitch, yaw, braking systems).

\subsubsection{System maintenance prediction}

Table 2 tabulates the expected number of repairs for all modelled components in the wind turbine. These statistics are gathered from the component analyses, as discussed in section 1.13.2.

\begin{tabular}{|c|c|c|c|c|c|c|c|}
\hline \multicolumn{2}{|c|}{ WT components } & \multicolumn{2}{|r|}{ Maintenance description } & \multirow{2}{*}{$\frac{\text { Min. }}{0}$} & \multirow{2}{*}{$\frac{\text { Max. }}{1}$} & \multirow{2}{*}{$\begin{array}{l}\text { Avg. } \\
0.01\end{array}$} & \multirow{2}{*}{$\begin{array}{l}\text { Std. } \\
0.10\end{array}$} \\
\hline \multirow{8}{*}{ Drivetrain } & \multirow{2}{*}{ Bearing } & Type 1 & Bearing replacement & & & & \\
\hline & & Type 4 & Repair of pitting, misalignment & 0 & 4 & 0.75 & 0.96 \\
\hline & \multirow{3}{*}{ Gearbox } & Type 2 & Gearbox replacement & 0 & 1 & 0.03 & 0.16 \\
\hline & & Type 3 & Gear replacement & 0 & 3 & 0.40 & 0.65 \\
\hline & & Type 4 & Gear tooth repair & 1 & 12 & 4.89 & 2.00 \\
\hline & \multirow[b]{2}{*}{ Shaft } & Type 1 & Shaft replacement & 0 & 0 & 0.00 & 0.00 \\
\hline & & Type 4 & $\begin{array}{l}\text { Minor repair, alignment } \\
\text { adjustment }\end{array}$ & 0 & 4 & 0.75 & 0.90 \\
\hline & Lubrication & Type 4 & Lubrication change & 0 & 11 & 4.37 & 1.79 \\
\hline \multirow{2}{*}{ Hydraulic } & $\begin{array}{l}\text { Hydraulic } \\
\text { pump }\end{array}$ & Type 3 & Part replacement & 1 & 14 & 6.58 & 2.24 \\
\hline & $\begin{array}{c}\text { Hydraulic } \\
\text { valves/pipes }\end{array}$ & Type 4 & Replacement & 1 & 15 & 6.58 & 2.40 \\
\hline \multirow[t]{2}{*}{ Braking } & $\begin{array}{c}\text { Brake } \\
\text { callipers/pads }\end{array}$ & Type 3 & Replace worn components & 0 & 7 & 2.16 & 1.54 \\
\hline & Brake discs & Type 3 & Replacement & 0 & 9 & 2.16 & 1.44 \\
\hline \multirow{3}{*}{ Yaw } & \multirow{2}{*}{ Yaw actuator } & Type 3 & Part replacement & 0 & 2 & 0.15 & 0.38 \\
\hline & & Type 4 & Minor repair & 0 & 9 & 3.00 & 1.68 \\
\hline & & Type 1 & Complete replacement & 0 & 1 & 0.01 & 0.07 \\
\hline
\end{tabular}




\begin{tabular}{|c|c|c|c|c|c|c|c|}
\hline & & Type 3 & Gear tooth repair & 0 & 2 & 0.13 & 0.36 \\
\hline & bearing/gear & Type 4 & Corrective repair & 0 & 10 & 3.08 & 1.83 \\
\hline & Yaw brake & Type 3 & Replacement & 0 & 9 & 3.22 & 1.70 \\
\hline \multirow{4}{*}{ Pitch } & \multirow{2}{*}{ Pitch actuator } & Type 3 & Part replacement & 0 & 3 & 0.47 & 0.64 \\
\hline & & Type 4 & Minor repair & 0 & 13 & 5.28 & 2.18 \\
\hline & \multirow{2}{*}{$\begin{array}{c}\text { Pitch } \\
\text { bearing/gear }\end{array}$} & Type 3 & Gear tooth repair/replacement & 0 & 3 & 0.52 & 0.67 \\
\hline & & Type 4 & Corrective repair & 1 & 12 & 5.29 & 2.11 \\
\hline \multirow{4}{*}{ Rotor } & \multirow{2}{*}{ Hub } & Type 1 & Replacement & 0 & 3 & 0.28 & 0.56 \\
\hline & & Type 4 & Minor corrosion repair & 0 & 9 & 3.79 & 1.82 \\
\hline & \multirow[b]{2}{*}{ Blade } & Type 1 & Replacement & 0 & 3 & 0.49 & 0.65 \\
\hline & & Type 5 & $\begin{array}{l}\text { Minor repair (patching, } \\
\text { sealing) }\end{array}$ & 1 & 12 & 5.21 & 2.08 \\
\hline \multirow{4}{*}{ Power } & \multirow{2}{*}{ Generator } & Type 2 & Part replacement & 0 & 8 & 2.67 & 1.59 \\
\hline & & Type 3 & Complete replacement & 0 & 2 & 0.06 & 0.24 \\
\hline & $\begin{array}{l}\text { Frequency } \\
\text { converter }\end{array}$ & Type 2 & Part/complete replacement & 1 & 13 & 5.92 & 2.27 \\
\hline & Transformer & Type 3 & Part/complete replacement & 0 & 12 & 5.90 & 2.12 \\
\hline \multirow{6}{*}{ Structure } & \multirow{2}{*}{ Tower } & Type 1 & Replacement & 0 & 1 & 0.01 & 0.07 \\
\hline & & Type 5 & Corrosion repair & 0 & 5 & 0.84 & 0.96 \\
\hline & \multirow{2}{*}{ Nacelle } & Type 1 & Replacement & 0 & 0 & 0.00 & 0.00 \\
\hline & & Type 5 & Loss of section, crack repair & 0 & 5 & 0.84 & 0.96 \\
\hline & \multirow[b]{2}{*}{ Foundation } & Type 1 & Replacement & 0 & 0 & 0.00 & 0.00 \\
\hline & & Type 5 & $\begin{array}{l}\text { Corrosion/repaint/remove } \\
\text { marine growth }\end{array}$ & 0 & 5 & 0.75 & 0.98 \\
\hline
\end{tabular}

Table 2: Statistics of the expected number of repairs for the wind turbine components

For offshore wind turbines, performing maintenance requires offshore access services which are usually provided by different types of ship or vessel. In this paper, there are appropriate vessels for each of the 5 maintenance types considered. The costs for these are also different and this information is given in Table A5 in the appendix. By tracking the number of times the token passes through place P356 in the model which represents the state where a ship is travelling to the site, the total of number of visits to the wind turbine for maintenance can be obtained. Figure 19 shows the average number of site visits for maintenance over a 40 year period for each type of maintenance (this does not include the number of visits for an inspection). It can also be seen that Crew Transfer Vessels (CTVs) (for type 4 and 5) are required for almost 41.04 times which is $57 \%$ out of the total number of site visits. 


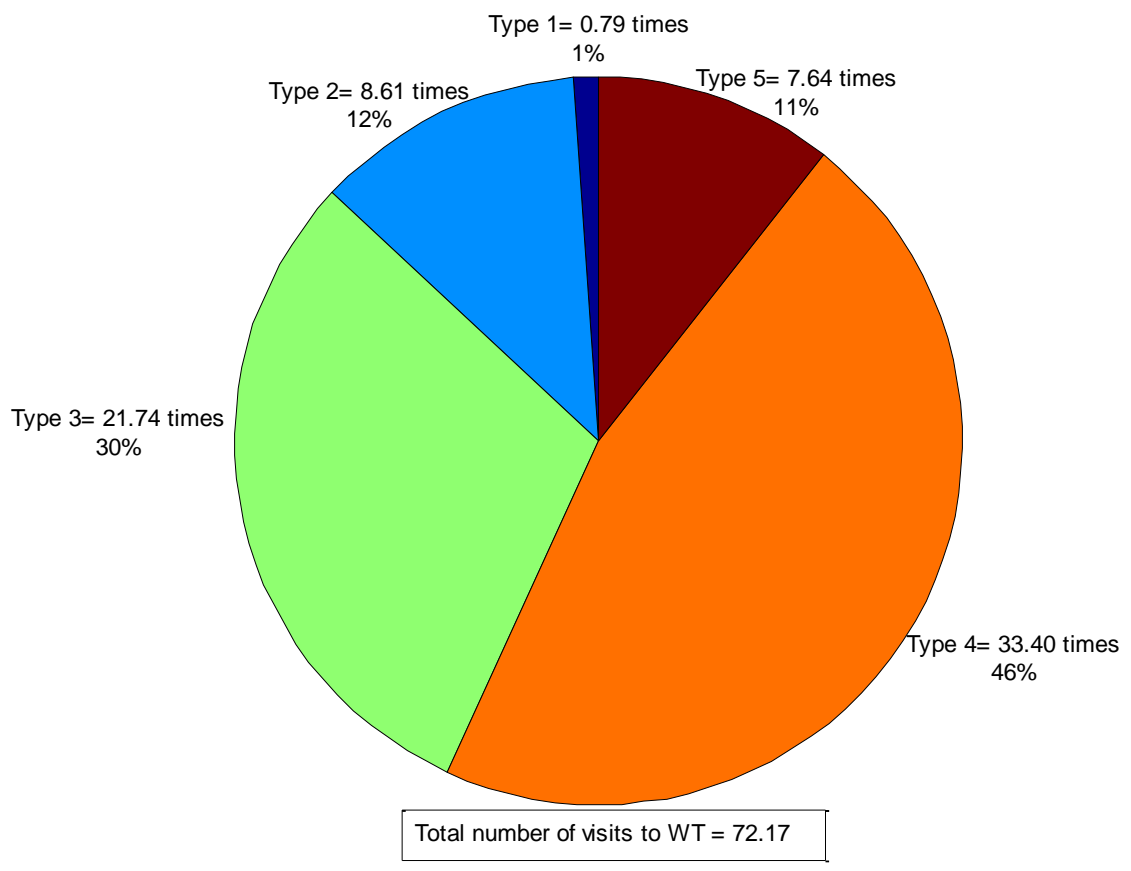

Figure 19: Total number of site visits for maintenance.

\subsubsection{Maintenance cost prediction}

Figure 20 shows the maintenance costs for each type of wind turbine component over the simulated life time. The maintenance cost is calculated based on the average cost of the repair action (Table A4), the typical cost of the offshore access service required for different maintenance actions (Table A5) and the number of repairs required over the component simulated lifetime (Table 2). Note that the average costs given in Table A4 in the appendix are estimated from several studies in the literature, these costs are assumed to cover the logistic cost, the material and the labour cost for that particular type of repair actions. It can be seen from the graph that the large contributions of the cost are from components with high failure rates (hydraulic pump, power system - generator, frequency converter and transformer) and from components with high replacement costs which require heavy lifting vessels to carry out maintenance tasks (blades, gearbox). 


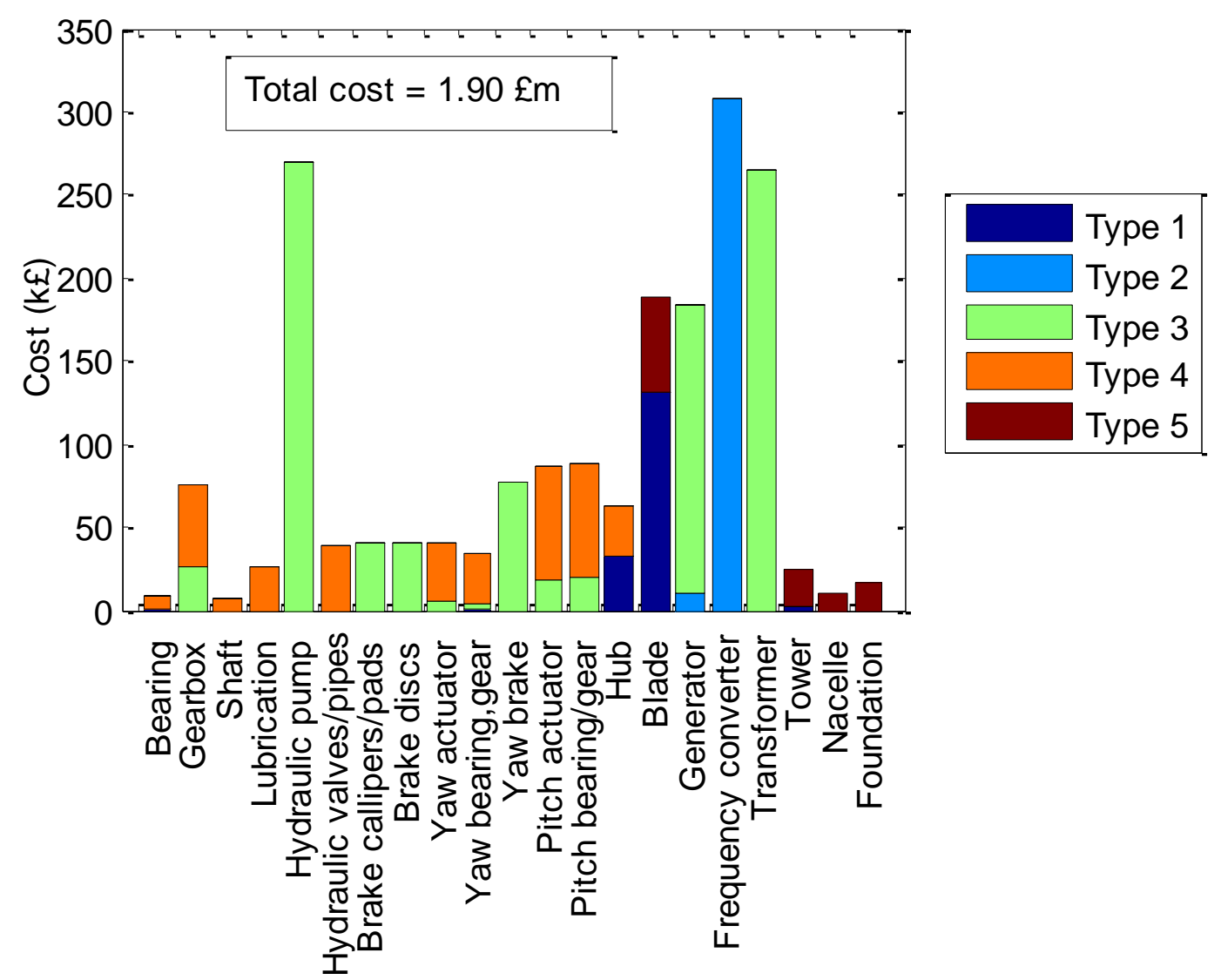

Figure 20: Maintenance costs for wind turbine components

\section{Conclusions}

This paper presents a wind turbine asset management model based on the Petri Net modelling method. The model captures stochastic processes relating to the degradation, maintenance and inspection processes of wind turbine components. The degradation processes of wind turbine subsystems and their components are considered to have different levels of degradation before functional failure. The use of condition monitoring systems is incorporated in the model for applicable components so that their condition is being continuously monitored. The effect of the early indication on the component failure is captured and maintenance action can be scheduled to prevent actual failure resulting in a wind turbine downtime. A Monte Carlo simulation procedure is applied to the model and relevant statistics are collected enabling various maintenance scenarios to be investigated. In particular, the model can be used to predict future component conditions, expected numbers of repairs, maintenance costs, number of component failures and failure times. A system level analysis also allows the average wind turbine downtime to be estimated as well as the contribution of the components to the wind turbine downtime and failure. The application of the model to a wind turbine is also presented in this paper, and this can be extended to model a complete wind farm. With the flexibility and power of the Petri Net modelling technique, the developed model presents an efficient method of managing wind turbine assets. 


\section{References}

1. RenewableUK, Offshore Wind Project Timelines Report, 2014.

2. McMillan, D. and G. Ault, Specification of reliability benchmarks for offshore wind farms. Proceedings of the European safety and reliability, 2008: p. 22-25.

3. Nilsson, J. and L. Bertling, Maintenance Management of Wind Power Systems Using Condition Monitoring Systems and Life Cycle Cost Analysis for Two Case Studies. Energy Conversion, IEEE Transactions on, 2007. 22(1): p. 223-229.

4. McMillan, D. and G. Ault, Condition monitoring benefit for onshore wind turbines: sensitivity to operational parameters. IET Renewable Power Generation, 2008. 2(1): p. 60-72.

5. Castro Sayas, F. and R. Allan. Generation availability assessment of wind farms. in Generation, Transmission and Distribution, IEE Proceedings-. 1996. IET.

6. Nilsson, J. and L. Bertling, Maintenance management of wind power systems using condition monitoring systems - life cycle cost analysis for two case studies. Energy Conversion, IEEE Transactions on, 2007. 22(1): p. 223-229.

7. Besnard, F. and L. Bertling, An approach for condition-based maintenance optimization applied to wind turbine blades. Sustainable Energy, IEEE Transactions on, 2010. 1(2): p. 77-83.

8. Eggen, A.O., et al. Handbook on condition monitoring of wind turbines. in Proc. of the European Wind Energy Conference 2009, Marseille, France, 16th-19th March. 2009.

9. Byon, E., L. Ntaimo, and Y. Ding, Optimal maintenance strategies for wind turbine systems under stochastic weather conditions. Reliability, IEEE Transactions on, 2010. 59(2): p. 393-404.

10. Pérez, E., et al. A stochastic DEVS wind turbine component model for wind farm simulation. in Proceedings of the 2010 Spring Simulation Multiconference. 2010. Society for Computer Simulation International.

11. Girault, C. and R. Valk, Petri nets for systems engineering: a guide to modeling, verification, and applications2002: Springer.

12. Tchakoua, P., et al., Wind Turbine Condition Monitoring: State-of-the-Art Review, New Trends, and Future Challenges. Energies, 2014. 7(4): p. 2595-2630.

13. Sheng, S. and P.S. Veers, Wind turbine drivetrain condition monitoring-an overview2011: National Renewable Energy Laboratory.

14. Fischer, K., F. Besnard, and L. Bertling, Reliability-centered maintenance for wind turbines based on statistical analysis and practical experience. Energy Conversion, IEEE Transactions on, 2012. 27(1): p. 184-195.

15. Zaher, A., et al., Online wind turbine fault detection through automated SCADA data analysis. Wind energy, 2009. 12(6): p. 574-593. 
16. Ribrant, J. and L. Bertling. Survey of failures in wind power systems with focus on Swedish wind power plants during 1997-2005. in Power Engineering Society General Meeting, 2007. IEEE. 2007. IEEE.

17. Ciang, C.C., J.-R. Lee, and H.-J. Bang, Structural health monitoring for a wind turbine system: a review of damage detection methods. Measurement Science and Technology, 2008. 19(12): p. 122001.

18. Kensche, C.W., Fatigue of composites for wind turbines. International Journal of Fatigue, 2006. 28(10): p. 1363-1374.

19. Nijssen, R.P.L., Fatigue life prediction and strength degradation of wind turbine rotor blade composites. Contractor Report SAND2006-7810P, Sandia National Laboratories, Albuquerque, NM, 2006.

20. Han, B.-H., et al., Damage assessment of wind turbine blade under static loading test using acoustic emission. Journal of Intelligent Material Systems and Structures, 2014. 25(5): p. 621-630.

21. Caselitz, P. and J. Giebhardt, Rotor condition monitoring for improved operational safety of offshore wind energy converters. Journal of Solar Energy Engineering, 2005. 127(2): p. 253-261.

22. Tavner, P., G. Van Bussel, and F. Spinato, Machine and converter reliabilities in wind turbines. 2006.

23. Spinato, F., et al., Reliability of wind turbine subassemblies. IET Renewable Power Generation, 2009. 3(4): p. 387-401.

24. Fischer, K., et al., Investigation of converter failure in wind turbines, in Elforsk report 2012.

25. Popa, L.M., et al. Condition monitoring of wind generators. in Industry Applications Conference, 2003. 38th IAS Annual Meeting. Conference Record of the. 2003. IEEE.

26. Papaelias, M., et al., Development and demonstration of a novel integrated condition monitoring system for wind turbines. 2009.

27. Ribrant, J., Reliability performance and maintenance-a survey of failures in wind power systems. Unpublished doctoral dissertation, XR-EE-EEK, 2006.

28. Maples, B., et al., Installation, Operation, and Maintenance Strategies to Reduce the Cost of Offshore Wind Energy. NREL, Denver, 2013.

29. Rademakers, L. and H. Braam, O\&M aspects of the $500 \mathrm{MW}$ offshore wind farm at NL7. ECN, Petten, 2002.

30. Vestas Wind Systems, Mechanical Operating and Maintenance Manual, 2007.

31. Petri, C.A., Fundamentals of a Theory of Asynchronous Information Flow. Proc. of IFIP Congress 62. --- Amsterdam: North Holland Publ. Comp., 1963: p. 386-390. 
32. Bause, F. and P.S. Kritzinger, Stochastic Petri Nets 2002: Springer.

33. Reisig, W. and G. Rozenberg, Lectures on Petri Nets I: Basic Models: Advances in Petri Nets. Vol. 1. 1998: Springer.

34. Andrews, J., A modelling approach to railway track asset management. Proceedings of the Institution of Mechanical Engineers, Part F: Journal of Rail and Rapid Transit, 2013. 227(1): p. 56-73.

35. Prescott DR, A.J., A Railway Track Ballast Maintenance and Inspection Model for Multiple Track Sections, in In Proceedings of PSAM 11 (Probablistic Safety Assessment and Management) / ESREL 2012 (European Safety and Reliabilty Conference)2012: Helsinki, Finland.

36. Le, B. and J. Andrews, Modelling Railway Bridge Asset Management using Petri-Net Modelling Techniques, in Proceedings of the Second International Conference on Railway Technology: Research, Development and Maintenance, J. Pombo, Editor 2014, Civil-Comp Press: Corsica, France.

37. Rubinstein, R.Y. and D.P. Kroese, Simulation and the Monte Carlo Method2011: Wiley.

38. Van Bussel, G. and M. Zaaijer. Reliability, availability and maintenance aspects of large-scale offshore wind farms, a concepts study. in Proceedings of MAREC. 2001.

39. Hahn, B., M. Durstewitz, and K. Rohrig, Reliability of wind turbines, in Wind energy2007, Springer. p. 329-332.

40. Van Bussel, G. and W. Bierbooms, The DOWEC Offshore Reference Windfarm: analysis of transportation for operation and maintenance. Wind Engineering, 2003. 27(5): p. 381-391.

41. Van Bussel, G. and C. Schöntag. Operation and maintenance aspects of large offshore windfarms. in Proceedings of the 1997 European Wind Energy Conference. 1997. Dublin, Ireland.

42. Fingersh, L.J., M.M. Hand, and A.S. Laxson, Wind turbine design cost and scaling model2006: National Renewable Energy Laboratory Golden, CO. 


\section{Appendix}

\begin{tabular}{|c|c|c|c|}
\hline & Components & Condition states & Maintenance type and action \\
\hline \multirow[t]{3}{*}{ Drivetrain } & Main bearings & $\begin{array}{l}\text { Degraded condition } \\
\text { Critical condition } \\
\text { Functional failure }\end{array}$ & $\begin{array}{l}\text { 4-repair of the pitting, misalignment } \\
\text { 1-bearing replacement } \\
\text { 1-bearing replacement }\end{array}$ \\
\hline & Gearbox & $\begin{array}{l}\text { Degraded condition } \\
\text { Critical condition } \\
\text { Functional failure }\end{array}$ & $\begin{array}{l}\text { 4-gear tooth repair } \\
\text { 3-gear replacement } \\
\text { 2-gearbox replacement }\end{array}$ \\
\hline & Main shafts & $\begin{array}{l}\text { Degraded condition } \\
\text { Critical condition } \\
\text { Functional failure }\end{array}$ & $\begin{array}{l}\text { 4-minor repair } \\
\text { 4-minor repair, adjust alignment } \\
\text { 1-shaft replacement }\end{array}$ \\
\hline \multirow[t]{2}{*}{$\begin{array}{l}\text { Hydraulic } \\
\text { system }\end{array}$} & Motor/gear pump & $\begin{array}{l}\text { Degraded condition } \\
\text { Functional failure }\end{array}$ & $\begin{array}{l}\text { 3-part replacement } \\
\text { 3-pump replacement }\end{array}$ \\
\hline & Valves/pipes & $\begin{array}{l}\text { Degraded condition } \\
\text { Functional failure }\end{array}$ & $\begin{array}{l}\text { 4-tightenning/replacement } \\
\text { 4-replacement }\end{array}$ \\
\hline \multirow[t]{2}{*}{ Brake system } & Callipers/pads & $\begin{array}{l}\text { Degraded condition } \\
\text { Functional failure }\end{array}$ & $\begin{array}{l}\text { 3-replace worn components } \\
\text { 3-replacement }\end{array}$ \\
\hline & Brake discs & $\begin{array}{l}\text { Degraded condition } \\
\text { Functional failure }\end{array}$ & $\begin{array}{l}\text { 3-replacement } \\
\text { 3-replacement }\end{array}$ \\
\hline \multirow[t]{3}{*}{ Yaw system } & Hydraulic actuator & $\begin{array}{l}\text { Degraded condition } \\
\text { Critical condition } \\
\text { Functional failure }\end{array}$ & $\begin{array}{l}\text { 4-minor repair } \\
\text { 3-part replacement } \\
\text { 3-complete replacement }\end{array}$ \\
\hline & Bearing/gear & $\begin{array}{l}\text { Degraded condition } \\
\text { Critical condition } \\
\text { Functional failure } \\
\end{array}$ & $\begin{array}{l}\text { 4-corrective repair } \\
\text { 3-gear tooth repair } \\
\text { 1-complete replacement }\end{array}$ \\
\hline & Yaw brake & $\begin{array}{l}\text { Degraded condition } \\
\text { Functional failure }\end{array}$ & $\begin{array}{l}\text { 3-part replacement } \\
\text { 3-complete replacement }\end{array}$ \\
\hline \multirow[t]{2}{*}{ Pitch system } & Hydraulic actuator & $\begin{array}{l}\text { Degraded condition } \\
\text { Critical condition } \\
\text { Functional failure }\end{array}$ & $\begin{array}{l}\text { 4-minor repair } \\
\text { 3-part replacement } \\
\text { 3-complete replacement }\end{array}$ \\
\hline & Bearing/gear & $\begin{array}{l}\text { Degraded condition } \\
\text { Critical condition } \\
\text { Functional failure }\end{array}$ & $\begin{array}{l}\text { 4-corrective repair } \\
\text { 3-gear tooth repair } \\
\text { 3-complete replacement }\end{array}$ \\
\hline Hub & & $\begin{array}{l}\text { Degraded condition } \\
\text { Critical condition } \\
\text { Functional failure }\end{array}$ & $\begin{array}{l}\text { 4-minor corrosion repair } \\
\text { 1-replacement } \\
\text { 1-replacement }\end{array}$ \\
\hline Blades & & $\begin{array}{l}\text { Degraded condition } \\
\text { Critical condition } \\
\text { Functional failure }\end{array}$ & $\begin{array}{l}\text { 5-minor repair (patching, sealing) } \\
\text { 1-replacement } \\
\text { 1-replacement }\end{array}$ \\
\hline \multirow[t]{3}{*}{$\begin{array}{l}\text { Power } \\
\text { system }\end{array}$} & Generator & $\begin{array}{l}\text { Degraded condition } \\
\text { Functional failure }\end{array}$ & $\begin{array}{l}\text { 3-part replacement } \\
\text { 2-complete replacement }\end{array}$ \\
\hline & Frequency converter & Functional failure & 2-part/complete replacement \\
\hline & Transformer & Functional failure & 3-part/complete replacement \\
\hline \multirow[t]{3}{*}{ Structure } & Tower & $\begin{array}{l}\text { Degraded condition } \\
\text { Critical condition } \\
\text { Functional failure }\end{array}$ & $\begin{array}{l}\text { 5-corrosion repair } \\
\text { 1-replacement } \\
\text { 1-replacement }\end{array}$ \\
\hline & Nacelle & $\begin{array}{l}\text { Degraded condition } \\
\text { Functional failure }\end{array}$ & $\begin{array}{l}\text { 5-loss of section, crack repair } \\
\text { 1-replacement }\end{array}$ \\
\hline & Foundation & $\begin{array}{l}\text { Degraded condition } \\
\text { Functional failure }\end{array}$ & $\begin{array}{l}\text { 5-corrosion/repaint/remove marine growth } \\
\text { 1-replacement }\end{array}$ \\
\hline
\end{tabular}

Table A1: Maintenance actions applied to different wind turbine components at different condition states. 


\begin{tabular}{|c|c|c|c|c|c|}
\hline Subsystem & Component & $\begin{array}{c}\text { Annual } \\
\text { Failure } \\
\text { Rate }\end{array}$ & $\begin{array}{c}\text { Degraded } \\
\text { Condition } \\
\text { (year) }\end{array}$ & $\begin{array}{c}\text { Critical } \\
\text { Condition } \\
\text { (year) }\end{array}$ & $\begin{array}{c}\text { Functional } \\
\text { Failure } \\
\text { (year) }\end{array}$ \\
\hline Drivetrain & Main bearings & 0.0050 & $\beta=1.2, \eta=160$ & $\beta=1.5, \eta=20$ & $\beta=1.5, \eta=20$ \\
\hline & Gearbox & 0.0500 & $\beta=1.3, \eta=16$ & $\beta=1.2, \eta=2$ & $\beta=1.4, \eta=2$ \\
\hline Hydraulic system & Motor/gear pump & 0.0050 & $\beta=1.2, \eta=160$ & $\beta=1.5, \eta=20$ & $\beta=1.5, \eta=20$ \\
\hline & Valves/pipes & 0.0610 & $\beta=1.2, \eta=13.11$ & - & $\beta=1.2, \eta=20$ \\
\hline Brake system & Callipers/pads & 0.0610 & $\beta=1.2, \eta=13.11$ & - & $\beta=1.2, \eta=3.28$ \\
\hline & Brake discs & 0.0189 & $\beta=1.2, \eta=42.28$ & - & $\beta=1.2, \eta=10.57$ \\
\hline Yaw system & Hydraulic actuator & 0.0189 & $\beta=1.2, \eta=42.28$ & - & $\beta=1.2, \eta=10.57$ \\
\hline & Bearing/gear & 0.0275 & $\beta=1.2, \eta=29.12$ & $\beta=1.2, \eta=3.64$ & $\beta=1.2, \eta=3.64$ \\
\hline & Yaw brake & 0.0275 & $\beta=1.2, \eta=29.12$ & $\beta=1.2, \eta=3.64$ & $\beta=1.2, \eta=3.64$ \\
\hline Pitch system & Hydraulic actuator & 0.0275 & $\beta=1.2, \eta=29.12$ & - & $\beta=1.2, \eta=7.28$ \\
\hline & Bearing/gear & 0.0520 & $\beta=1.2, \eta=15.38$ & $\beta=1.2, \eta=1.92$ & $\beta=1.2, \eta=1.92$ \\
\hline Hub & Hub & 0.0520 & $\beta=1.2, \eta=15.38$ & $\beta=1.2, \eta=1.92$ & $\beta=1.2, \eta=1.92$ \\
\hline Blades & Blades & 0.0348 & $\beta=1.2, \eta=23.02$ & $\beta=1.2, \eta=2.88$ & $\beta=1.2, \eta=2.88$ \\
\hline Power system & Generator & 0.0520 & $\beta=1.2, \eta=15.38$ & $\beta=1.2, \eta=1.92$ & $\beta=1.2, \eta=1.92$ \\
\hline & Frequency converter & 0.0240 & $\beta=1.2, \eta=33.38$ & - & $\beta=1.2, \eta=8.35$ \\
\hline & Transformer & 0.0670 & - & - & $\beta=1.2, \eta=14.93$ \\
\hline Structure & Tower & 0.0670 & - & - & $\beta=1.2, \eta=14.93$ \\
\hline & Nacelle & 0.0060 & $\beta=1.2$, & $\beta=1.2, \eta=16.67$ & $\beta=1.2, \eta=16.67$ \\
\hline & Foundation & 0.0060 & $\begin{array}{c}\eta=1.2, \\
\eta=133.33\end{array}$ & $\beta=1.2, \eta=16.67$ & $\beta=1.2, \eta=16.67$ \\
\hline CMS & CMS & 0.0060 & $\beta=1.2$, & $\beta=1.2, \eta=16.67$ & $\beta=1.2, \eta=16.67$ \\
\hline & & & $\eta=133.33$ & & - \\
\hline
\end{tabular}

Table A2: Model input parameters - degradation distributions for transitions T1-T72.

Distributions are Weibull distributions characterised by shape parameter $\beta$, and scale parameter $\eta$ (unit: year). References: [16, 17, 23-25, 38-41].

In the event of real application then data would be collected to provide the times to achieve different levels of degradation. This data would then be used to determine the parameters of the appropriate Weibull parameters. In the paper, the Weibull distributions that govern the transition process between degradation states are indicative and were estimated from the failure rate data obtained from several published studies. In the study presented a relatively crude estimation was used so that the characteristic time $(\eta)$ of a component residing in the normal, degraded and critical states cover $80 \%, 10 \%$ and $10 \%$ respectively of the characteristic life of the component (the characteristic life of the component is estimated as the inverse of the failure rate). The shape parameters $(\beta)$ of the distributions are assumed to be larger than 1 to effectively capture with the increasing deterioration rates of mechanical components.

\begin{tabular}{|c|c|c|c|c|}
\hline $\begin{array}{c}\text { Repair } \\
\text { type }\end{array}$ & $\begin{array}{c}\text { Logistic time } \\
\text { (h) }\end{array}$ & $\begin{array}{c}\text { Repair time } \\
\text { (h) }\end{array}$ & $\begin{array}{c}\text { Travel/access time } \\
\text { (h) }\end{array}$ & $\begin{array}{c}\text { Wait for good weather time } \\
\text { (weeks) }\end{array}$ \\
\hline 5 & 8 & 3 & 3 & $\beta=3.2, \eta=6$ \\
\hline 4 & 24 & 3 & 3 & $\beta=3.3, \eta=1$ \\
\hline 3 & 48 & 10 & 3 & $\beta=3.4, \eta=2$ \\
\hline 2 & 160 & 50 & 3 & $\beta=3.5, \eta=3$ \\
\hline 1 & 500 & 70 & 3 & $\beta=3.1, \eta=6$ \\
\hline
\end{tabular}

Table A3: Model input parameters - maintenance process. The model assumes a work shift of 8 hours per day. 


\begin{tabular}{|c|c|c|c|c|}
\hline \multicolumn{2}{|c|}{ WT components } & \multicolumn{2}{|r|}{ Maintenance description } & \multirow{2}{*}{$\begin{array}{c}\text { Cost (f) } \\
20,000\end{array}$} \\
\hline \multirow{8}{*}{ Drivetrain } & \multirow{2}{*}{ Bearing } & Type 1 & Bearing replacement & \\
\hline & & Type 4 & Repair of pitting, misalignment & 5,000 \\
\hline & \multirow{3}{*}{ Gearbox } & Type 2 & Gearbox replacement & 260,000 \\
\hline & & Type 3 & Gear replacement & 50,000 \\
\hline & & Type 4 & Gear tooth repair & 5,000 \\
\hline & \multirow{2}{*}{ Shaft } & Type 1 & Shaft replacement & 37,000 \\
\hline & & Type 4 & Minor repair, alignment adjustment & 5,000 \\
\hline & Lubrication & Type 4 & Lubrication change & 1,000 \\
\hline \multirow{2}{*}{ Hydraulic } & Hydraulic pump & Type 3 & Part replacement & 26,000 \\
\hline & Hydraulic valves/pipes & Type 4 & Replacement & 1,000 \\
\hline \multirow{2}{*}{ Braking } & Brake callipers/pads & Type 3 & Replace worn components & 4,000 \\
\hline & Brake discs & Type 3 & Replacement & 4,000 \\
\hline \multirow{6}{*}{ Yaw } & \multirow{2}{*}{ Yaw actuator } & Type 3 & Part replacement & 20,000 \\
\hline & & Type 4 & Minor repair & 7,000 \\
\hline & \multirow{3}{*}{ Yaw bearing/gear } & Type 1 & Complete replacement & 9,000 \\
\hline & & Type 3 & Gear tooth repair & 7,000 \\
\hline & & Type 4 & Corrective repair & 5,000 \\
\hline & Yaw brake & Type 3 & Replacement & 9,000 \\
\hline \multirow{4}{*}{ Pitch } & \multirow{2}{*}{ Pitch actuator } & Type 3 & Part replacement & 23,000 \\
\hline & & Type 4 & Minor repair & 8,000 \\
\hline & \multirow{2}{*}{ Pitch bearing/gear } & Type 3 & Gear tooth repair/replacement & 23,000 \\
\hline & & Type 4 & Corrective repair & 8,000 \\
\hline \multirow{4}{*}{ Rotor } & \multirow{2}{*}{ Hub } & Type 1 & Replacement & 44,000 \\
\hline & & Type 4 & Minor corrosion repair & 3,000 \\
\hline & \multirow{2}{*}{ Blade } & Type 1 & Replacement & 200,000 \\
\hline & & Type 5 & Minor repair (patching, sealing) & 4,000 \\
\hline \multirow{4}{*}{ Power } & \multirow{2}{*}{ Generator } & Type 2 & Complete replacement & 150,000 \\
\hline & & Type 3 & Part replacement & 50,000 \\
\hline & Frequency converter & Type 2 & Part/complete replacement & 12,000 \\
\hline & Transformer & Type 3 & Part/complete replacement & 30,000 \\
\hline \multirow{6}{*}{ Structure } & \multirow{2}{*}{ Tower } & Type 1 & Replacement & 264,000 \\
\hline & & Type 5 & Corrosion repair & 20,000 \\
\hline & \multirow{2}{*}{ Nacelle } & Type 1 & Replacement & 40,000 \\
\hline & & Type 5 & Loss of section, crack repair & 5,000 \\
\hline & \multirow{2}{*}{ Foundation } & Type 1 & Replacement & 204,000 \\
\hline & & Type 5 & Corrosion/repaint/remove marine growth & 15,000 \\
\hline
\end{tabular}

Table A4: Typical maintenance costs for different repair types. These costs are estimated from several studies $[2,6,40]$ in the literature and where the maintenance cost is not available the costs are estimated from the installation and construction costs [42] for a new wind turbine. 


\begin{tabular}{|c|l|c|}
\hline $\begin{array}{c}\text { Maint. } \\
\text { types }\end{array}$ & \multicolumn{1}{|c|}{ Typical vessel requires } & Typical rate (f) \\
\hline 5 & $\begin{array}{l}\text { Crew Transfer Vessels (CTVs): these are fast and small vessels which transfer } \\
\text { technicians, tools and spare parts (1-1.5 ton capacity) to the wind turbine for minor } \\
\text { repairs and/or inspections. }\end{array}$ & 7,000 \\
\hline 4 & Crew Transfer Vessels (CTVs). & 5,000 \\
\hline 3 & Jack-up vessels: these are self-propelled vessels with jack-up platforms. & 15,000 \\
\hline 2 & $\begin{array}{l}\text { Jack-up barges: these are non-self-propelled vessels with jack-up platforms.. These } \\
\text { vessels have better stability for crane operation under rough weather conditions but } \\
\text { are slow and dependent on the support ships to tow to working position. }\end{array}$ & 40,000 \\
\hline 1 & $\begin{array}{l}\text { Crane ships: these are heavy lifting ships with sheer leg or pedestal mounted cranes } \\
\text { to life heavy loads. }\end{array}$ & 70,000 \\
\hline
\end{tabular}

Table A5: Special vessels for different types of repairs and typical cost [40] for a shift 